\title{
Anatomía de la madera de ocho especies de Quercus (FAGACEAE) de Oaxaca, México
}

\author{
Carmen de la Paz Pérez Olvera ${ }^{1}$ \\ Susana Vélez Jiménez ${ }^{1}$ \\ Jacqueline Ceja Romero ${ }^{1}$
}

\begin{abstract}
RESUMEN
Se presenta la descripción anatómica, macroscópica y microscópica de la madera de ocho especies de Quercus provenientes del estado de Oaxaca: Q. affinis Scheidw., Q. conzatti Trel., Q. laurina Humb. \& Bonpl., Q. scytophylla Liebm., pertenecientes a la Sección Lobatae (encinos rojos) y Q. glabrescens Benth., Q. obtusata Humb. \& Bonpl., Q. peduncularis Née y Q. rugosa Née, ubicadas dentro de la Sección Quercus (encinos blancos). Se muestreó un ejemplar por especie en los municipios de Capulalpam de Méndez y San Pedro Yolox del estado de Oaxaca. Para el estudio macroscópico se usaron muestras de $12 \mathrm{~cm} \times 7 \mathrm{~cm} \times 1 \mathrm{~cm}$ y para el microscópico se hicieron laminillas fijas de cortes y de material disociado. La madera se obtuvo de una troza de 1,30 m cortada de base a copa. Tanto las tablillas como los cortes se hicieron en los tres planos de la madera: transversal, tangencial y radial. A los elementos mensurables se les aplicó un análisis estadístico univariado y se clasificaron con base en la media. Se observaron diferencias en el color de la madera, en el tipo de porosidad, en la distribución y abundancia de los poros, en el tamaño y abundancia de los radios multiseriados y en la presencia y cantidad de los contenidos celulares (cristales, gomas y tílides) entre las especies de los dos subgéneros.
\end{abstract}

PALABRAS CLAVE:

Anatomía, madera, Oaxaca, Quercus.

\begin{abstract}
The macroscopic and microscopic anatomical description of the wood of eight species of Quercus from Oaxaca are presented: Q. affinis Scheidw., Q. conzatti Trel., Q. laurina Humb. \& Bonpl., Q. scytophylla Liebm. of the section Lobatae (red oaks) and Q. glabrescens Benth., Q. obtusata Humb. \& Bonpl., Q. peduncularis Née y Q. rugosa Née of the section Quercus (white oaks). One tree per species was recolected in the Capulalpam de Méndez and San Pedro Yolox municipalities of the Oaxaca State. The macroscopic study was made in wood samples of $12 \mathrm{~cm} \mathrm{x} 7 \mathrm{~cm} \times 1 \mathrm{~cm}$ and for the microscopic study slides of dissociated material and cuts were used. The material was obtained from logs of 1,30 m length which were cut from the base to the crown. Samples of wood and slides showing the typical planes of wood were made. For the quantitative elements an univariate statistic analysis was carried out. On their turn, these were classified on the basis of average values. Differences in wood color, type of porosity, size and distribution of pores, abundance of multiseriate rays size and cellular contents (crystals, gums and tylosis) between the species of both subgenus were observed.
\end{abstract}

KEY WORDS:

Anatomy, wood, Oaxaca, Quercus. 


\section{INTRODUCCIÓN}

En México, las especies de encinos constituyen uno de los recursos forestales maderables más abundantes de los bosques de clima templado (Rzedowski, 1981). Se han registrado entre 135 y 140 especies (Nixon, 1993; Valencia, 2004). Sin embargo, la mayoría de ellas son taladas sin un adecuado plan de manejo, lo que altera negativamente los ecosistemas en que crecen y por consecuencia, se desaprovecha este valioso recurso forestal (De la Paz Pérez, 2000). Entre las causas principales de este desperdicio están: la falta de una selección de las especies y su posible utilización de acuerdo con sus características anatómicas, así como la aplicación de técnicas inadecuadas en los procesos de aprovechamiento acordes con las propiedades tecnológicas de la madera.

Los estados que tienen mayor número de especies de Quercus y en los cuales se explotan más son: Chihuahua, Durango, Jalisco, Michoacán, Guerrero, Oaxaca, Puebla y Veracruz (Zavala, 1990, 1995; INEGI, 2000; De la Paz Pérez et al., 2000). Sin embargo, es importante mencionar que la industrialización del recurso está muy por debajo de lo que pudiera obtenerse si se consideraran las características propias de cada especie y se aplicaran los tiempos y normas apropiadas para su procesamiento e industrialización, sobre todo en el aserrío y en el secado (De la Paz Pérez, 2000).

Existen algunos trabajos relativos a la anatomía de la madera de algunos taxa de Quercus, con material recolectado en varios estados de la República (De la Paz Pérez, 1974, 1976, 1982, 1985, 2000; Corral, 1981; Guerrero, 1985; De la Paz Pérez y Quintanar, 1994; Quintanar et al., 1996). Sin embargo, éste es el primer trabajo que estudia la anatomía de espe- cies de Oaxaca, que por otra parte, es el estado más rico en especies del género para el país (Valencia, 2004).

\section{OBJETIVO}

El objetivo de este trabajo es conocer y comparar las propiedades anatómicas de la madera de ocho especies del género Quercus que crecen en el estado de Oaxaca: Q. affinis Scheidw., Q. conzatti Trel., Q. laurina Humb. \& Bonpl., Q. scytophylla Liebm. (encinos rojos), $Q$. glabrescens Liebm., Q. obtusata Humb. \& Bonpl., Q. peduncularis Née y Q. rugosa Née (encinos blancos). Ya que se considera que el manejo y el aprovechamiento de la madera de encino, depende del conocimiento de las características estructurales de la misma, como son las descripciones anatómicas completas.

\section{METODOLOGÍA}

El material de las especies se obtuvo de ocho árboles recolectados en un bosque de pino-encino, en los municipios de Capulalpam de Méndez y de San Pedro Yolox, Oaxaca (Fig. 1). Los ejemplares de respaldo se depositaron en el Herbario Metropolitano UAMIZ "Dr. Ramón Riba y Nava" y en el Herbario del INIFAP "Luciano Vela Gálvez". Las muestras de madera se registraron en la Xiloteca UAMIZ y en la Xiloteca del INIFAP (Tabla 1).

De cada árbol se cortó una troza de 1,30 m de longitud; a la altura de 1,30 m se cortaron dos rodajas de $2 \mathrm{~cm}$ de grosor en las que se muestrearon cuatro cubos de $2 \times 2 \times 2 \mathrm{~cm}$, tanto de la albura como del duramen. Los cubos se ablandaron a ebullición en agua destilada, aproximadamente durante 30 horas y de ellos se obtuvieron cortes de 15 a $20 \mu \mathrm{m}$ de grosor, en los planos transversal, tangencial y radial. 


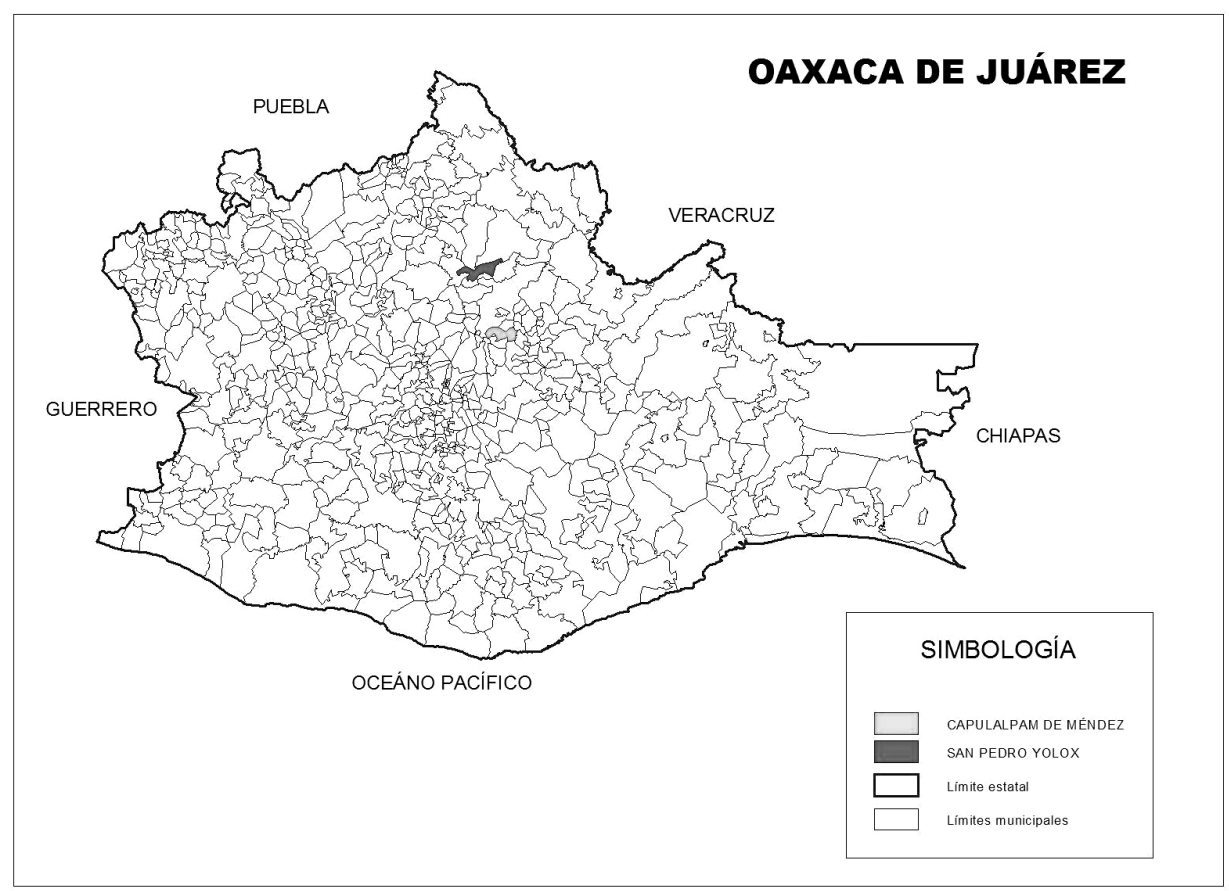

Figura 1. Ubicación de los municipios de recolecta del material

Tabla 1. Registro de las especies estudiadas

\begin{tabular}{|c|c|c|c|c|c|}
\hline \multirow[b]{2}{*}{$\begin{array}{l}\text { Nombre } \\
\text { científico }\end{array}$} & \multirow{2}{*}{ Subgénero } & \multirow[b]{2}{*}{$\begin{array}{l}\text { Nombre } \\
\text { común }\end{array}$} & \multicolumn{3}{|c|}{ Registro } \\
\hline & & & Municipio & Xiloteca & Herbario \\
\hline Q. affinis & \multirow{4}{*}{$\begin{array}{l}\text { Erythrobalanus } \\
\text { (encinos rojos) }\end{array}$} & $\begin{array}{l}\text { Hoja } \\
\text { blanca }\end{array}$ & Capulalpam & $M-180$ & 52127 \\
\hline Q. conzatti & & Cucharita & Capulalpam & M-179 & 52126 \\
\hline Q. laurina & & Encino & Yolox & $X-169$ & 16664 \\
\hline Q. scytophylla & & $\begin{array}{l}\text { Hoja } \\
\text { blanca }\end{array}$ & Capulalpam & $M-178$ & 52125 \\
\hline Q. glabrescens & \multirow{4}{*}{$\begin{array}{c}\text { Leucobalanus } \\
\text { (encinos } \\
\text { blancos) }\end{array}$} & Roble & Yolox & $X-197$ & 12654 \\
\hline Q. obtusata & & Roble & Capulalpam & M-181 & 52128 \\
\hline Q. peduncularis & & Roble & Yolox & $X-200$ & 12657 \\
\hline Q. rugosa & & Roble & Yolox & $X-201$ & 12658 \\
\hline
\end{tabular}


Los cortes se tiñeron con verde yodo durante dos minutos, se lavaron con agua destilada y se deshidrataron en alcoholes al $30 \%, 50 \%, 70 \%, 96 \%$ y $100 \%$, realizándose dos cambios de cinco minutos en cada uno, posteriormente se colocaron en xilol, y finalmente se montaron con resina sintética.

De los cubos se cortaron pequeñas virutas tanto de la albura como del duramen, las cuales se colocaron por separado en tubos de ensaye agregando en estos la solución de Jeffrey (Johansen, 1940). Luego, el material se lavó con agua destilada en varias ocasiones, hasta eliminar por completo la mezcla. Una vez disociado se tiñó con pardo de Bismarck y se hicieron preparaciones fijas montándolas con gelatina glicerinada. Las descripciones microscópicas se hicieron de acuerdo con IAWA Committee (1989). Los elementos mensurables fueron sometidos a un análisis estadístico univariado y se clasificaron con base en la media.

Del resto de la troza se obtuvieron tablillas de $15 \times 7 \times 1 \mathrm{~cm}$ que se emplearon para describir las características macroscópicas usando las tablas de clasificación de Tortorelli (1956) y para el color, las tablas de Munsell (1990). Para cada especie se describió: el color, el olor, el sabor, el brillo, el veteado, la textura, el hilo y la visibilidad de los elementos celulares.

Los nombres comunes, las características botánicas y los datos de distribución se dieron conforme a Martínez (1981) y Zavala (1995). De acuerdo con las características anatómicas de la madera se sugieren usos específicos para las especies.

\section{Sitios de recolección}

El municipio de Capulalpam de Méndez, Oaxaca (Fig.1), se localiza entre las coordenadas $17^{\circ} 18^{\prime}$ de latitud Norte y $96^{\circ} 27^{\prime}$ de longitud Oeste, en la Provincia Fisiográfica Sierra Madre del Sur, Subprovincia Sierras Orientales. El clima es templado húmedo con abundantes lluvias en verano $\mathrm{C}(\mathrm{m})$, la temperatura media anual es de $22{ }^{\circ} \mathrm{C}$, la precipitación media es de $1500 \mathrm{~mm}$ y su altitud promedio es de 2040 msnm. Limita hacia el Sur con los municipios de Laxapa, Xiacui y Natividad; al Este y Noreste con el municipio de Ixtlán; al Norte con el municipio de Yotao, y al Oeste con los municipios de Juquila, Vijanos y Yalina (INEGI, 1990).

Las especies recolectadas en este municipio fueron: $Q$. affinis, $Q$. conzatti, $Q$. obtusata y $Q$. scytophylla, en la localidad de Río de los Pavos en un bosque de pino-encino a una altitud de 2500 msnm.

El municipio de San Pedro Yolox (Fig. 1), se localiza entre las coordenadas $17^{\circ} 35^{\prime}$ de latitud Norte y $96^{\circ} 33^{\prime}$ de longitud Oeste, en la Provincia Fisiográfica Sierra Madre del Sur, Subprovincia Sierras Orientales. El clima es templado húmedo con abundantes lluvias en verano $C(m)$, la temperatura media anual es de $22^{\circ} \mathrm{C}$, la precipitación media es de $1500 \mathrm{~mm}$ y su altitud promedio es de 1940 msnm. Limita hacia el Sureste con el municipio de Comaltepec; al Oeste con el municipio de Quitepec y, al Norte con los municipios de Usila y Valle Nacional (INEGI, 1990).

Las especies recolectadas en este municipio fueron: $Q$. glabrescens, $Q$. laurina, $Q$. peduncularis y $Q$. rugosa, en la localidad de El Carrizal en un bosque de pino-encino a una altitud de $2650 \mathrm{msnm}$. 


\section{RESULTADOS}

\section{Descripción de las especies}

\section{ENCINOS ROJOS}

FAGACEAE, Subgénero Erythrobalanus, Sección Lobatae

1. Quercus affinis Scheidw. (Lám. 1)

Nombres comunes: Encino, encino laurelillo, encino roble, manzanillo, encino de hoja delgada, titzmol, shishihuilón, encino de hoja blanca.

Distribución: Nuevo León, Tamaulipas, San Luis Potosí, Guanajuato, Querétaro, Hidalgo, México, Distrito Federal, Tlaxcala, Puebla, Veracruz y Oaxaca.

Características botánicas (Lám. 1a)

Árbol de 6 a $12 \mathrm{~m}$ de alto, con ramillas de $2 \mathrm{~mm}$ de diámetro, de color pardo rojizo con lenticelas pequeñas y pálidas. Hojas delgadas, tiesas y brillantes, elíptico-acuminadas o lanceoladasoblongas, de 4,5 a $9 \mathrm{~cm}$ de largo por 1,5 a $2 \mathrm{~cm}$ de ancho, lisas en ambas caras, margen dentado desde la región media hasta el ápice. Fruto (bellota) ovoide, de $13 \mathrm{~mm}$ de largo, anual o bianual, solitarios o por pares sobre un pedúnculo de 8 $\mathrm{mm}$ de largo.

Características macroscópicas de la madera (Tabla 2 y Lám. 1b-1c)

La madera no presenta diferencia de color entre la albura y el duramen, es de color blanco rosáceo (7.5YR 8/2). Los radios multiseriados son de color castaño rojizo (2.5YR 5/2) contrastando con los demás elementos celulares. No tiene olor ni sabor, el brillo es mediano, el veteado es pronunciado, la textura es gruesa y el hilo es recto. Los anillos de crecimiento están marcados por una hilera de fibras.

Características microscópicas de la madera (Tabla 2 y Lám. 1d-1f)

La madera presenta porosidad semianular, los poros de la madera temprana son más grandes que los de la madera tardía. A través del anillo se ve un cambio gradual del tamaño de los poros. Los poros son exclusivamente solitarios y se arreglan en hileras radiales. Son poco numerosos, de contorno oval, de diámetro tangencial mediano en la madera temprana y pequeño en la tardía. Los elementos de vaso son de longitud mediana, con platina de perforación simple, paredes terminales oblicuas y punteaduras areoladas alternas de forma oval. Las punteaduras vaso-radio son simples, con bordes reducidos y arreglo vertical. Alrededor de algunos vasos de la madera temprana se encuentran traqueidas vasicéntricas. Pocos vasos presentan tílides. El parénquima axial es difuso en agregados. Los radios son uniseriados y multiseriados, homogéneos, formados por células procumbentes. Los primeros son numerosos, la mayoría de 13 células de altura. Los multiseriados son poco numerosos, altos $y$ anchos. Las fibras son de tipo libriforme y fibrotraqueidas, de longitud mediana, diámetro fino y pared mediana. 

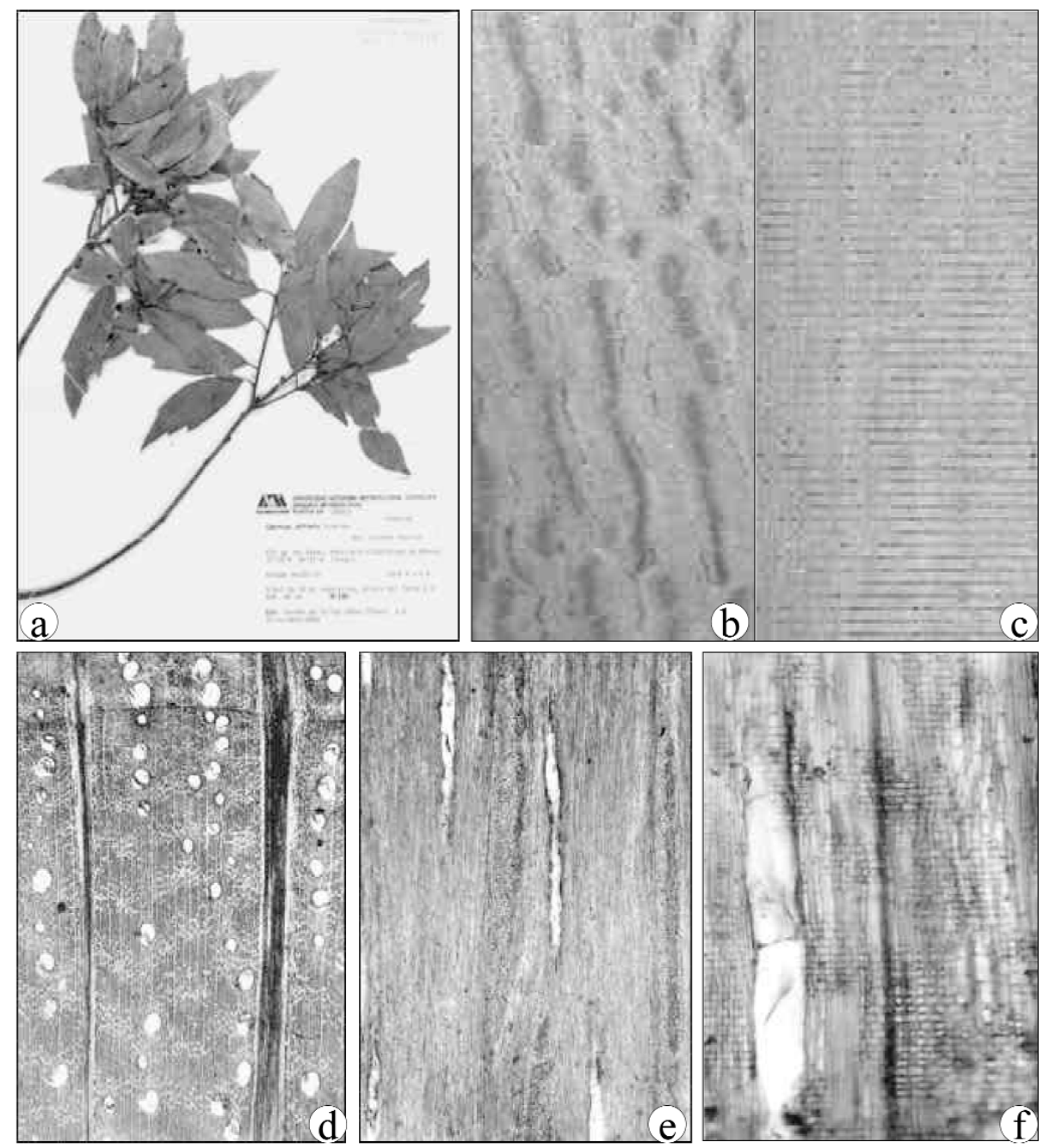

Lámina 1. Quercus affinis Scheidw. (a) Ejemplar de herbario. (b) Tablilla tangencial. (c) Tablilla radial. (d) Corte transversal (2,5x). (e) Corte tangencial $(2,5 x)$.

(f) Corte radial $(10 x)$ 


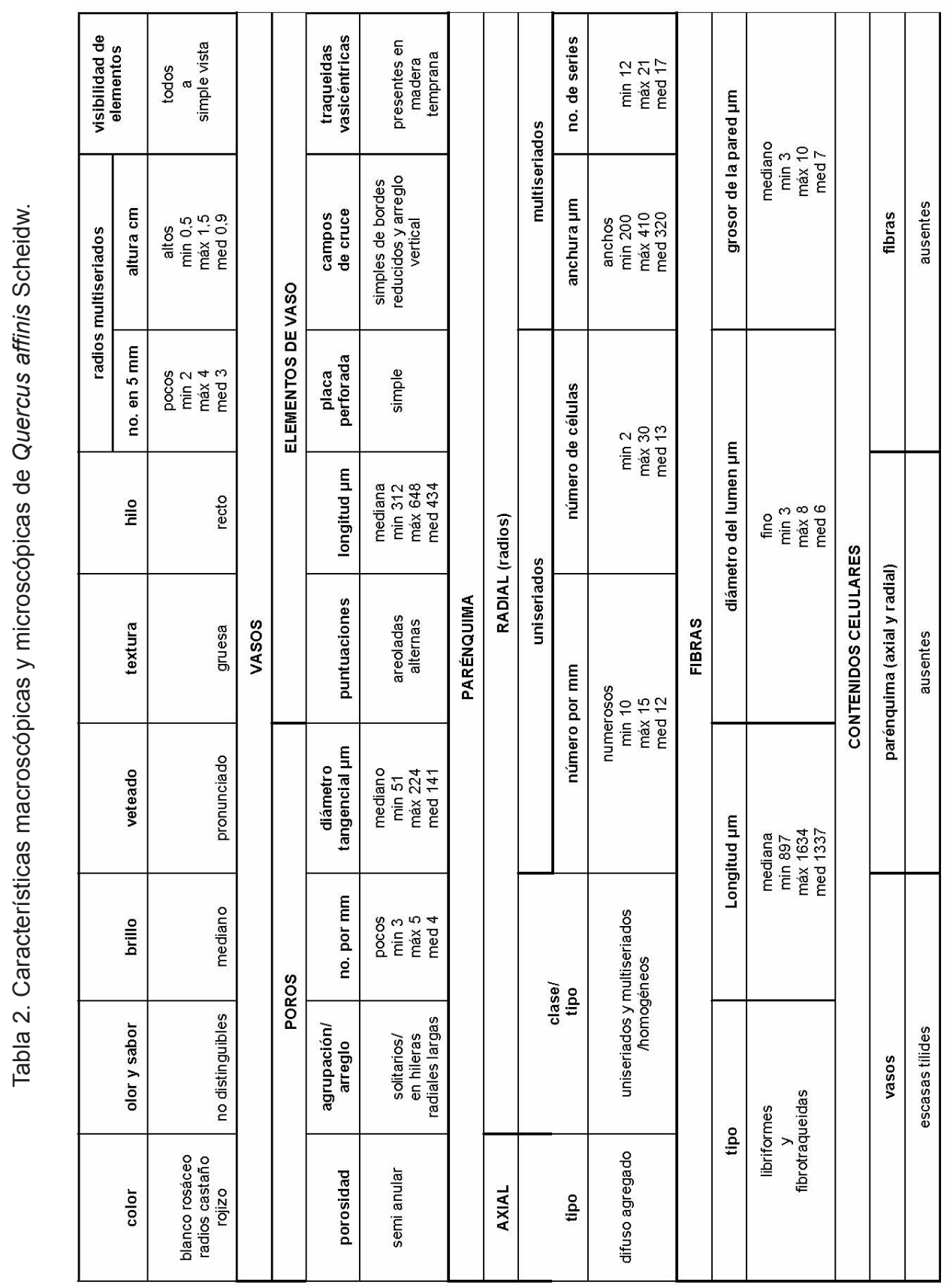


2. Quercus conzatti Trel. (Lám. 2)

Nombres comunes: Cucharita.

Distribución: Oaxaca.

Características botánicas (Lám. 2a)

Árbol de 8 a $10 \mathrm{~m}$ de alto con ramillas fuertes, acanaladas y con lenticelas numerosas. Hojas de 9 a $12 \mathrm{~cm}$ de largo por poco menos de ancho, orbiculares a algo obovadas, haz brillante y liso, envés densamente tomentoso, margen entero o con dientes terminados en cerdas delgadas y cortas principalmente hacia el ápice. Fruto (bellota) ovoide, de $10 \mathrm{~mm}$ de largo, anual, varios agrupados en un eje de 4 a $5 \mathrm{~cm}$ de largo.

Características macroscópicas de la madera (Tabla 3 y Lám. 2b-2c)

La madera no presenta diferencia de color entre albura y duramen, es de color rosa (7.5YR 7/3), los radios multiseriados son de color rojo pálido (10R 6/4) contrastando con los demás elementos celulares. No tiene olor ni sabor, el brillo es mediano, el veteado pronunciado, la textura gruesa y el hilo recto. Los anillos de crecimiento están marcados por una hilera de fibras.
Características microscópicas de la madera (Tabla 3 y Lám. 2d-2f)

La madera presenta porosidad semianular, los poros de la madera temprana son un poco más grandes que los de la madera tardía. Los poros son exclusivamente solitarios y se arreglan en hileras radiales. Son poco numerosos, de contorno oval y circular, de diámetro tangencial mediano en la mayoría y pequeño en algunos poros de la madera tardía. Los elementos de vaso son de longitud mediana, con platina de perforación simple, paredes terminales oblicuas y punteaduras areoladas alternas de forma oval. Las punteaduras vaso-radio son simples, con bordes reducidos y arreglo vertical. Alrededor de algunos vasos de la madera temprana se encuentran traqueidas vasicéntricas. Pocos vasos presentan tílides. El parénquima axial es difuso en agregados. Los radios son uniseriados y multiseriados, homogéneos, formados por células procumbentes. Los primeros son numerosos, de 14 células de altura. Los multiseriados son poco numerosos, altos y anchos. Los radios uniseriados presentan escasos cristales de forma romboidal. Las fibras son de tipo libriforme y fibrotraqueidas, de longitud mediana, diámetro fino y pared mediana. 

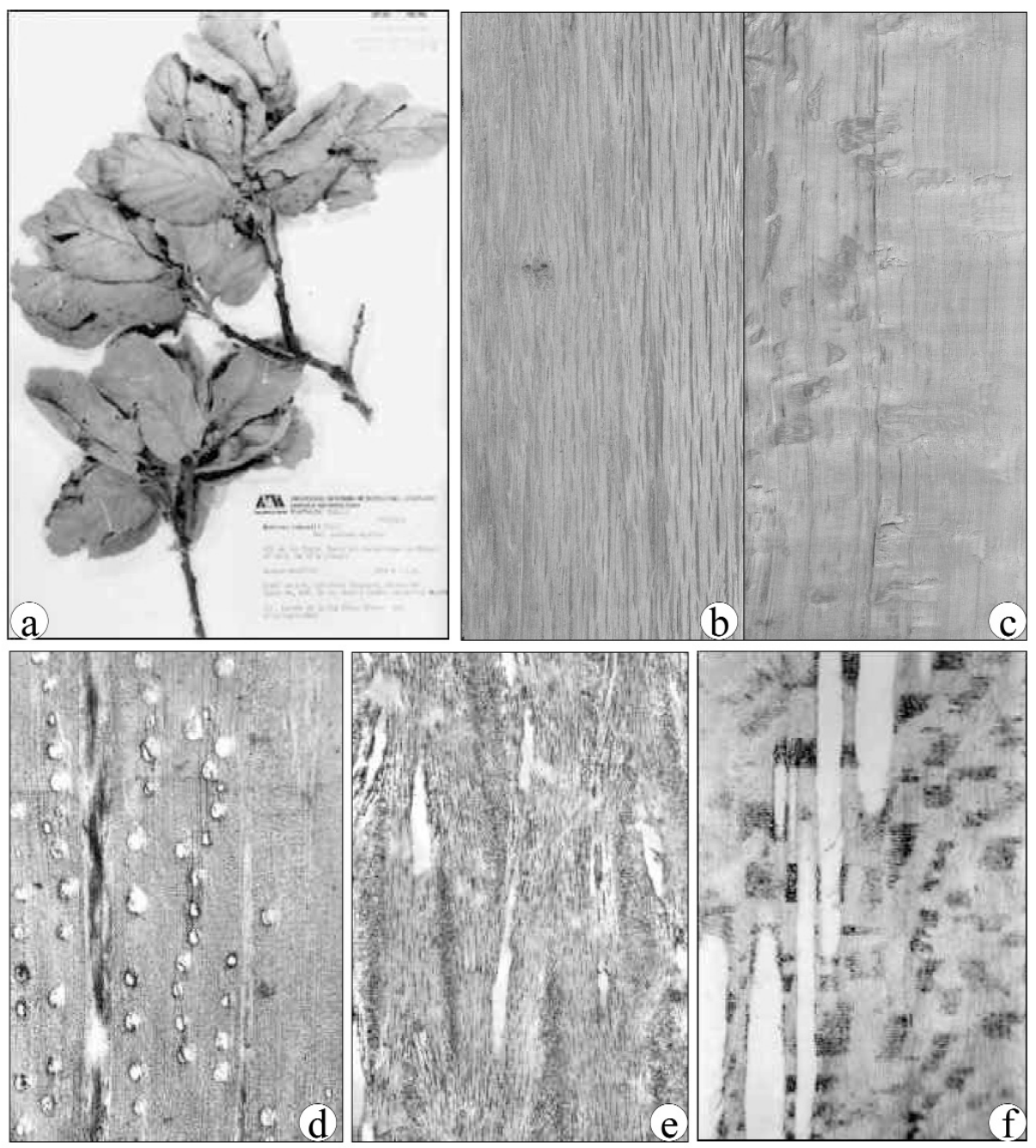

Lámina 2. Quercus conzatti Trel. (a) Ejemplar de herbario. (b) Tablilla tangencial. c. Tablilla radial. (d) Corte transversal (2,5x). (e) Corte tangencial $(2,5 x)$.

(f) Corte radial $(10 \mathrm{x})$ 


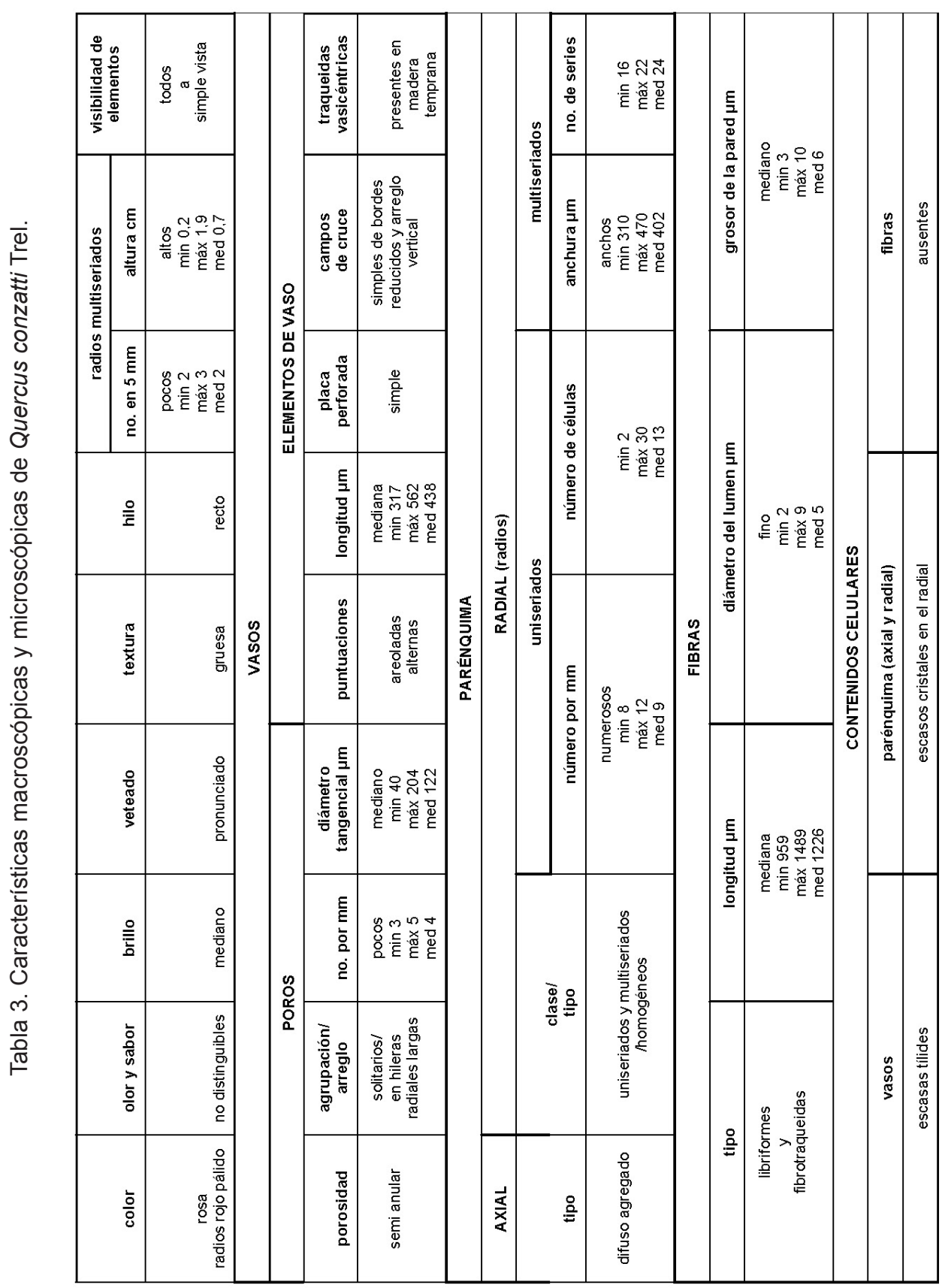


3. Quercus laurina Humb. \& Bonpl. (Lám. 3)

Nombres comunes: Chilillo, encino laurelillo, encino hoja angosta, encino roble, encino colorado, encino blanco, encino prieto, encino uricua, atlualpitzahual, xicatahua, tesmolera y huitzalacate.

Distribución: Tamaulipas, Durango, San Luis Potosí, Sinaloa, Nayarit, Jalisco, Colima, Michoacán, Guerrero, Oaxaca, Chiapas, Aguascalientes, Guanajuato, Querétaro, Hidalgo, Tlaxcala, México, Distrito Federal, Morelos, Puebla y Veracruz.

Caracteristicas botánicas (Lám. 3a)

Árbol de 10 a $25 \mathrm{~m}$ de alto, con ramillas de $2,3 \mathrm{~mm}$ de diámetro, de color rojo oscuro con lenticelas pequeñas. Hojas deciduas, anchamente lanceoladas u oblanceoladas, de 7 a $10 \mathrm{~cm}$ de largo por 2,5 a $3 \mathrm{~cm}$ de ancho, haz liso y brillante, envés con pubescencia lanosa en las axilas, margen entero con dos dientes aristados a cada lado cerca del ápice. Fruto (bellota) ovoide, de $12 \mathrm{~mm}$ de largo, bianual, solitario o por pares sobre un pedúnculo de 5 a $15 \mathrm{~mm}$ de largo.

Características macroscópicas de la madera (Tabla 4 y Lám. 3b-3c)

La madera no presenta diferencia de color entre albura y duramen, es de color castaño rojizo claro (5YR 6/4), los radios multiseriados son de color castaño rojizo (2,5YR 5/3) contrastando con los demás elementos celulares. No tiene olor ni sabor característicos, el brillo es mediano, el veteado pronunciado, la textura gruesa y el hilo recto. Los anillos de crecimiento están marcados por una hilera de fibras y poros de mayor diámetro que los del resto del anillo.

Características microscópicas de la madera (Tabla 4 y Lám. 3d-3f)

La madera presenta porosidad semianular, los poros de la madera temprana son más grandes que los de la madera tardía, forman de una a dos hileras. Los poros son exclusivamente solitarios y se arreglan en hileras radiales y diagonales. Son poco numerosos, de contorno oval y circular, de diámetro tangencial mediano en la madera temprana y pequeño en la tardía. Los elementos de vaso son de longitud mediana, con platina de perforación simple, paredes terminales oblicuas y punteaduras areoladas alternas de forma oval. Las punteaduras vaso-radio son simples, con bordes reducidos y arreglo vertical. Alrededor de algunos vasos de la madera temprana se encuentran traqueidas vasicéntricas. El parénquima axial es difuso en agregados. Algunas células presentan cristales de forma romboidal. Los radios son uniseriados y multiseriados, homogéneos, formados por células procumbentes. Los primeros son numerosos, de 11 células de altura. Los multiseriados son poco numerosos, altos y anchos. Presentan gran cantidad de taninos. Las fibras son de tipo libriforme y fibrotraqueidas, de longitud mediana, diámetro fino y pared mediana. 


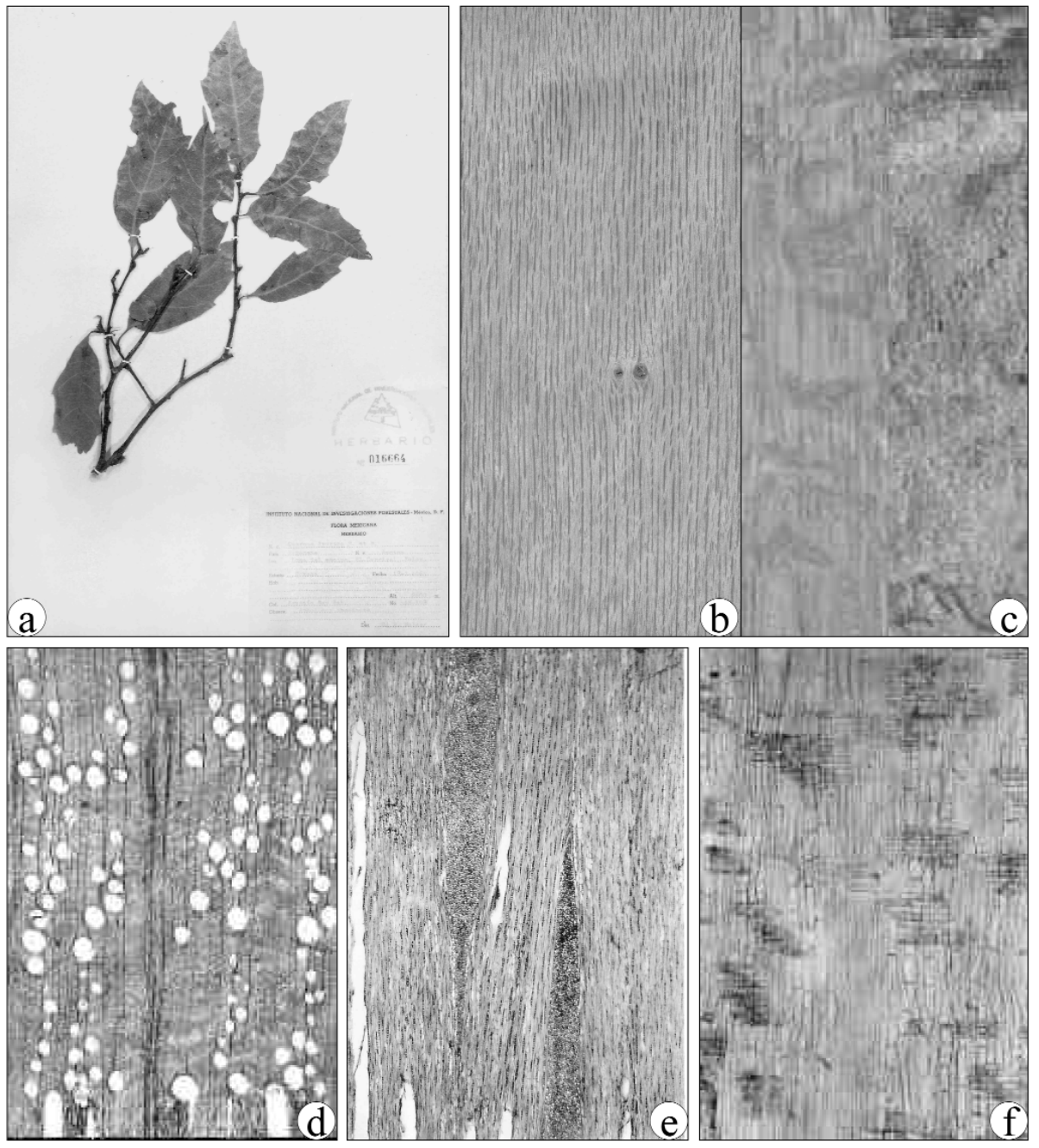

Lámina 3. Quercus laurina Humb. \& Bonpl. (a) Ejemplar de herbario. (b) Tablilla tangencial. (c) Tablilla radial. (d) Corte transversal (2,5x). (e) Corte tangencial $(2,5 x)$. (f) Corte radial $(10 x)$ 


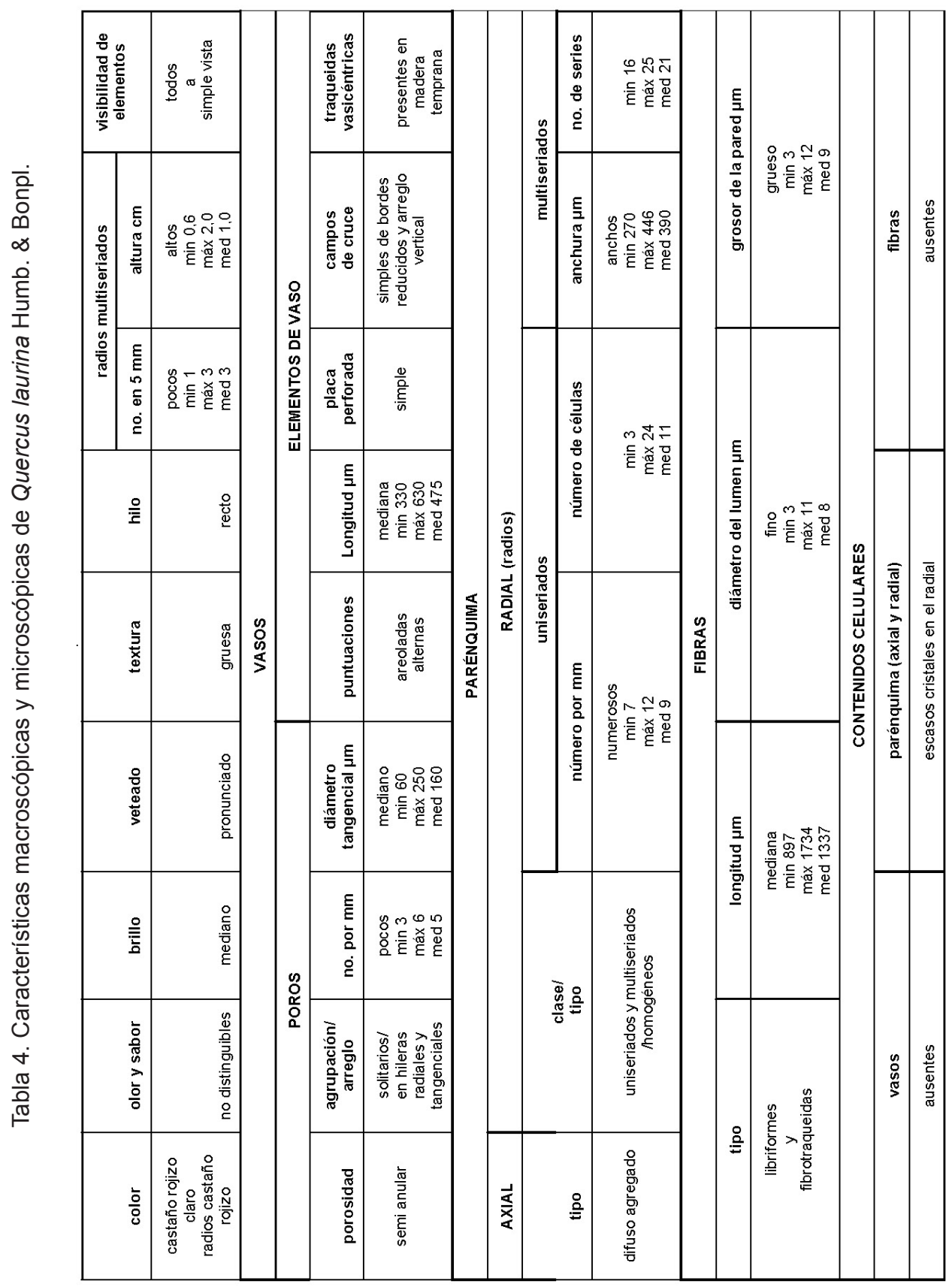


4. Quercus scytophylla Liebm. (Lám. 4)

Nombres comunes: encino prieto, encino blanco, encino rosillo y encino de hoja blanca.

Distribución: Sonora, Chihuahua, Durango, Sinaloa, Jalisco, Michoacán, Guerrero, Oaxaca, Chiapas, México y Puebla.

Características botánicas (Lám. 4a)

Árbol hasta de $20 \mathrm{~m}$ de alto, con el tronco de 40 a $70 \mathrm{~cm}$ de diámetro, con ramillas de $3 \mathrm{~mm}$ de diámetro, de color castaño oscuro, con lenticelas pequeñas y ovales. Hojas elípticas, agudas, de 7 a 15 hasta $20 \mathrm{~cm}$ de largo por 7 a 9 de ancho, haz liso, envés densamente blanco tomentoso, margen con dientes aristados irregularmente dispuestos o a veces entero. Fruto (bellota) ovoide, de 12 a $13 \mathrm{~mm}$ de largo, bianual, solitario o en grupos sobre un pedúnculo de 3-6 $\mathrm{mm}$ de largo.

Características macroscópicas de la madera (Tabla 5 y Lám. 4b-3c)

La madera no presenta diferencia de color entre albura y duramen, es de color castaño muy pálido (5YR 7/3), los radios multiseriados son de color gris rojizo (10R 6/1) contrastando con los demás elementos celulares. No tiene olor ni sabor, el brillo es mediano, el veteado pronunciado, la textura gruesa y el hilo recto. Los anillos de crecimiento están marcados por una hilera de fibras.

Características microscópicas de la madera (Tabla 5 y Lám. 4d-4f)

La madera presenta porosidad difusa. Los poros son exclusivamente solitarios y se arreglan en hileras radiales. Son poco numerosos, de contorno oval y circular, de diámetro tangencial mediano. Los elementos de vaso son de longitud mediana, con platina de perforación simple, paredes terminales oblicuas y punteaduras areoladas alternas de forma oval. Las punteaduras vaso-radio son simples, con bordes reducidos y arreglo vertical. Alrededor de algunos vasos de la madera temprana se encuentran traqueidas vasicéntricas. El parénquima axial es difuso en agregados. Los radios son uniseriados y multiseriados, homogéneos, formados por células procumbentes. Los primeros son numerosos, de 12 células de altura. Los multiseriados son poco numerosos, altos y muy anchos. Las fibras son de tipo libriforme y fibrotraqueida, de longitud mediana, diámetro fino y pared gruesa. 

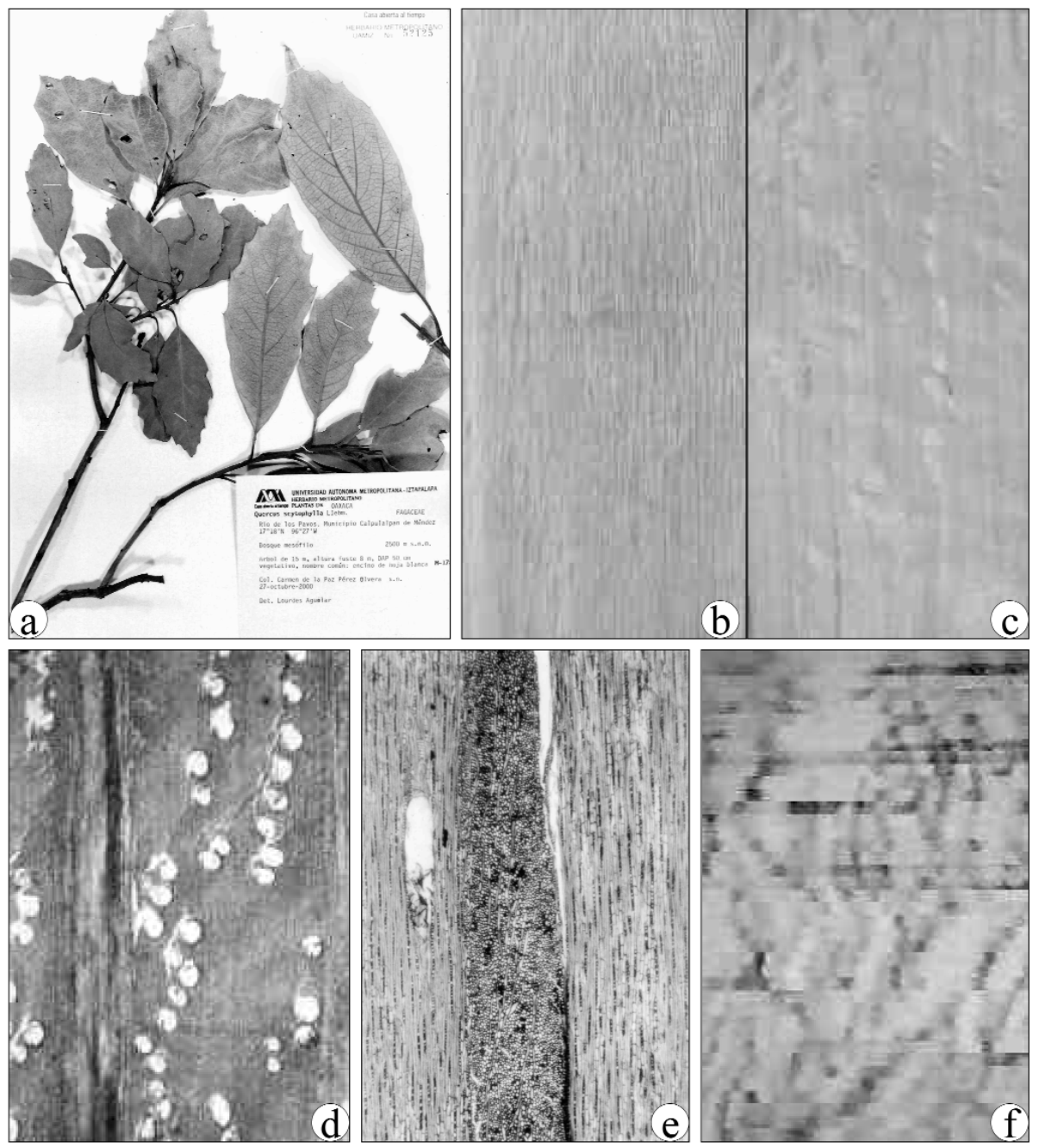

Lámina 4. Quercus scytophylla Liebm. (a) Ejemplar de herbario. (b) Tablilla tangencial. (c) Tablilla radial. (d) Corte transversal $(2,5 x)$. (e) Corte tangencial $(2,5 x)$.

(f) Corte radial $(10 x)$ 


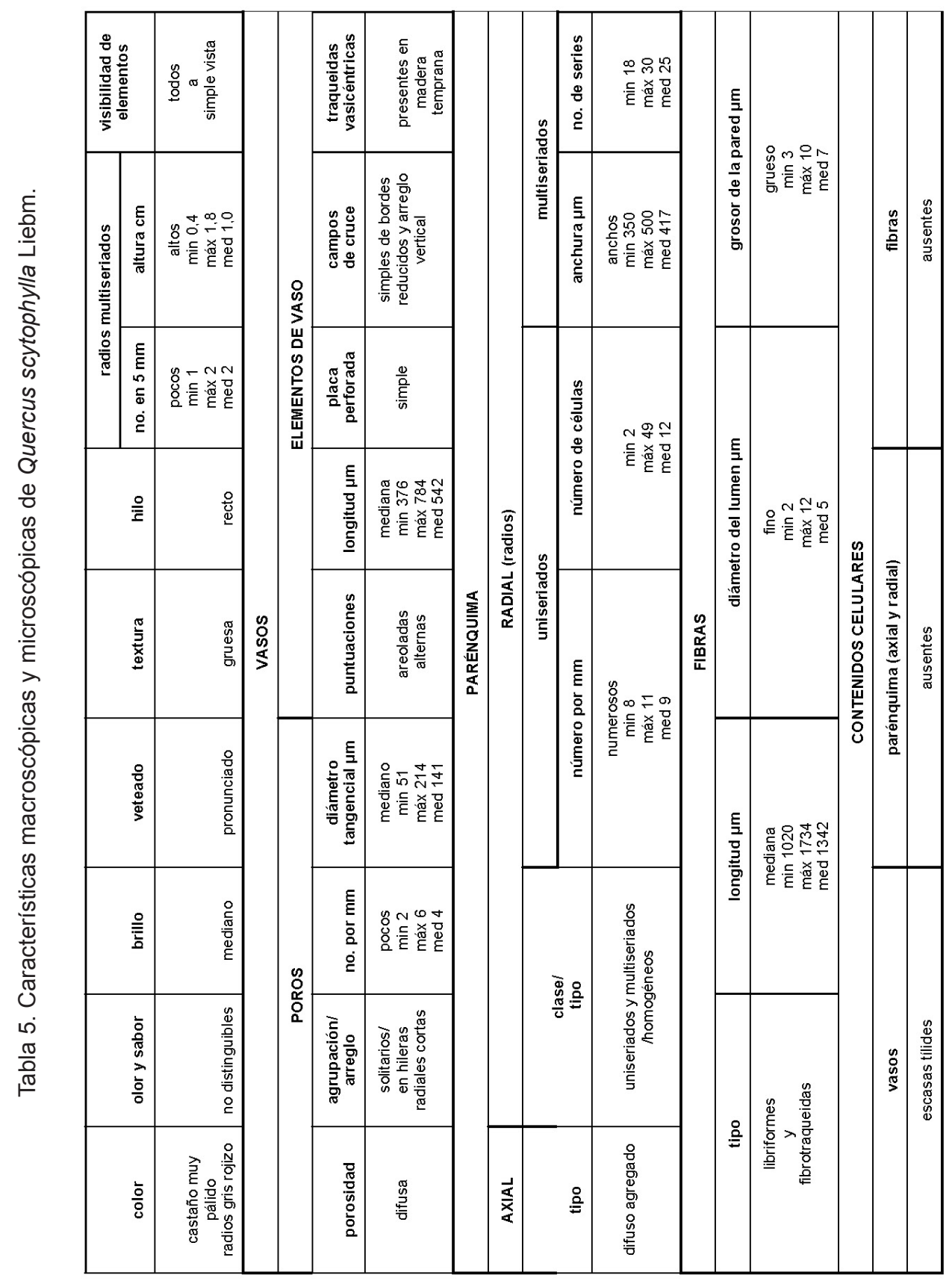




\section{ENCINOS BLANCOS}

FAGACEAE, Subgénero Leucobalanus, Sección Quercus

5. Quercus glabrescens Benth. (Lám. 5)

Nombres comunes: encino, encino blanco y quebracho.

Distribución: San Luis Potosí, Michoacán, Oaxaca, Hidalgo, México, Morelos, Tlaxcala, Puebla y Veracruz.

Características botánicas (Lám. 5a)

Árbol de 6 a $20 \mathrm{~m}$ de alto, con ramillas de $3 \mathrm{~mm}$ de diámetro, de color castaño rojizo a grisáceo, con lenticelas de color amarillo. Hojas oblanceoladas o elípticooblanceoladas, de 7 a $5 \mathrm{~cm}$ de largo por 1 a 2 de ancho, margen con 2 a 4 dientes a cada lado, haz brillante y glabro, envés verde brillante y glabro, margen fuertemente revoluto, con dos a cuatro dientes a cada lado hacia la mitad superior de la hoja. Fruto (bellota) ovoide, de $15 \mathrm{~mm}$ de largo, anual, solitario, con pedúnculo de $3,5 \mathrm{~cm}$ de largo.

Características macroscópicas de la madera (Tabla 6 y Lám. 5b-4c)

La madera no presenta diferencia de color entre albura y duramen, es de color castaño amarillo claro (10YR 6/4), los radios multiseriados son de color castaño oscuro (10YR 4/3) contrastando con los demás elementos celulares. No tiene olor ni sabor, el brillo es mediano, el veteado pronunciado, la textura gruesa y el hilo recto. Los anillos de crecimiento están marcados por una hilera de fibras.

Características microscópicas de la madera (Tabla 6 y Lám. 5d-5f)

La madera presenta porosidad difusa. Los poros son exclusivamente solitarios y se arreglan en hileras radiales largas. Son poco numerosos, de contorno oval y circular, de diámetro tangencial mediano. Los elementos de vaso son de longitud mediana, con platina de perforación simple, paredes terminales oblicuas y punteaduras areoladas alternas de forma oval. Las punteaduras vaso-radio son simples, con bordes reducidos y arreglo vertical. Alrededor de algunos vasos de la madera temprana se encuentran traqueidas vasicéntricas. La mayoría de los vasos presentan tílides. El parénquima axial es difuso en agregados. Los radios son uniseriados y multiseriados, homogéneos, formados por células procumbentes. Los primeros son numerosos, de 11 células de altura. Los multiseriados son poco numerosos, altos y extremadamente anchos. Presentan pocos cristales de forma romboidal. Las fibras son de tipo libriforme y fibrotraqueidas, de longitud mediana, diámetro fino y pared gruesa. 


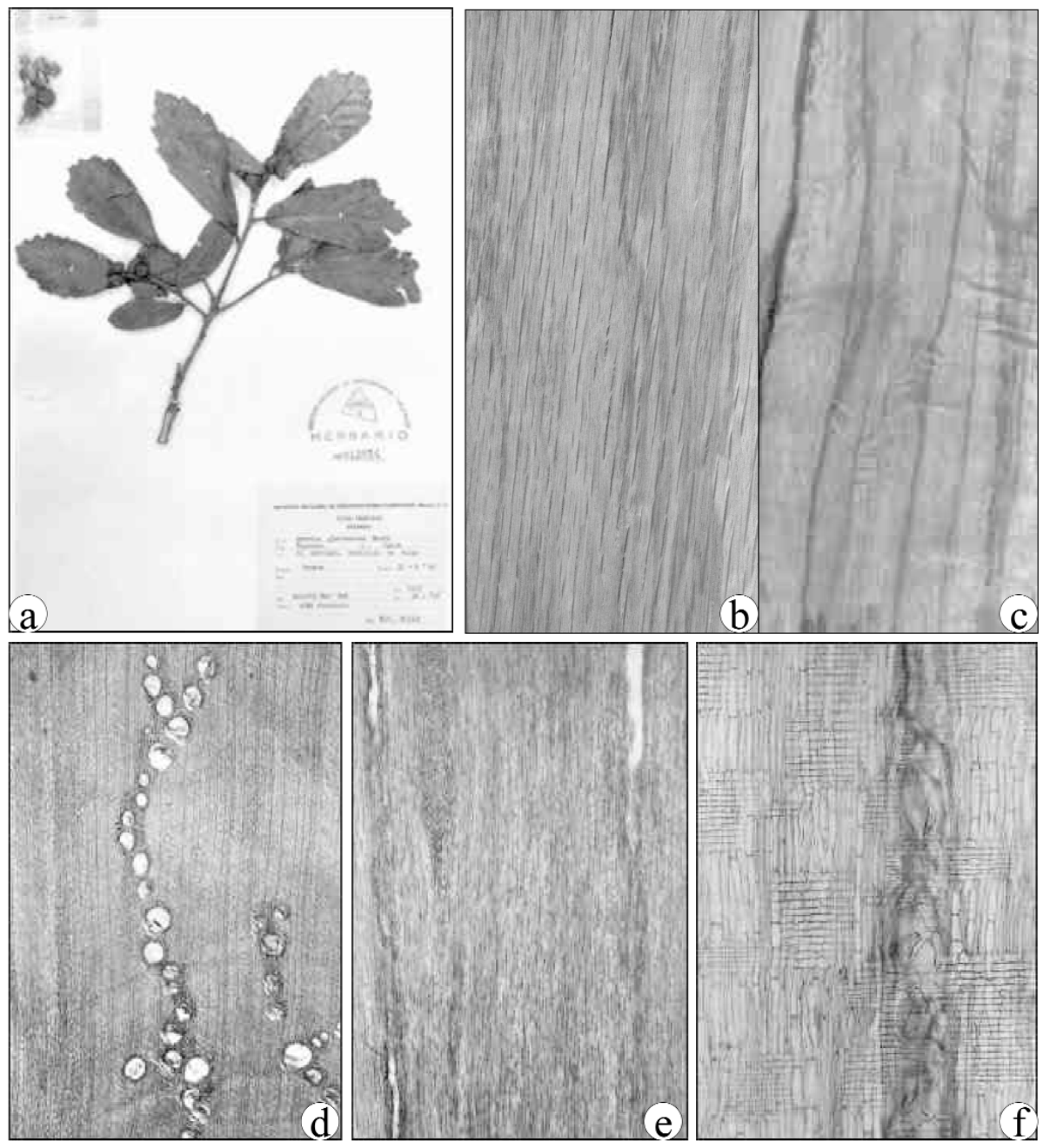

Lámina 5. Quercus glabrescens Benth. (a) Ejemplar de herbario. (b) Tablilla tangencial. (c) Tablilla radial. (d) Corte transversal (2,5x). (e) Corte tangencial $(2,5 x)$.

(f) Corte radial $(10 x)$ 


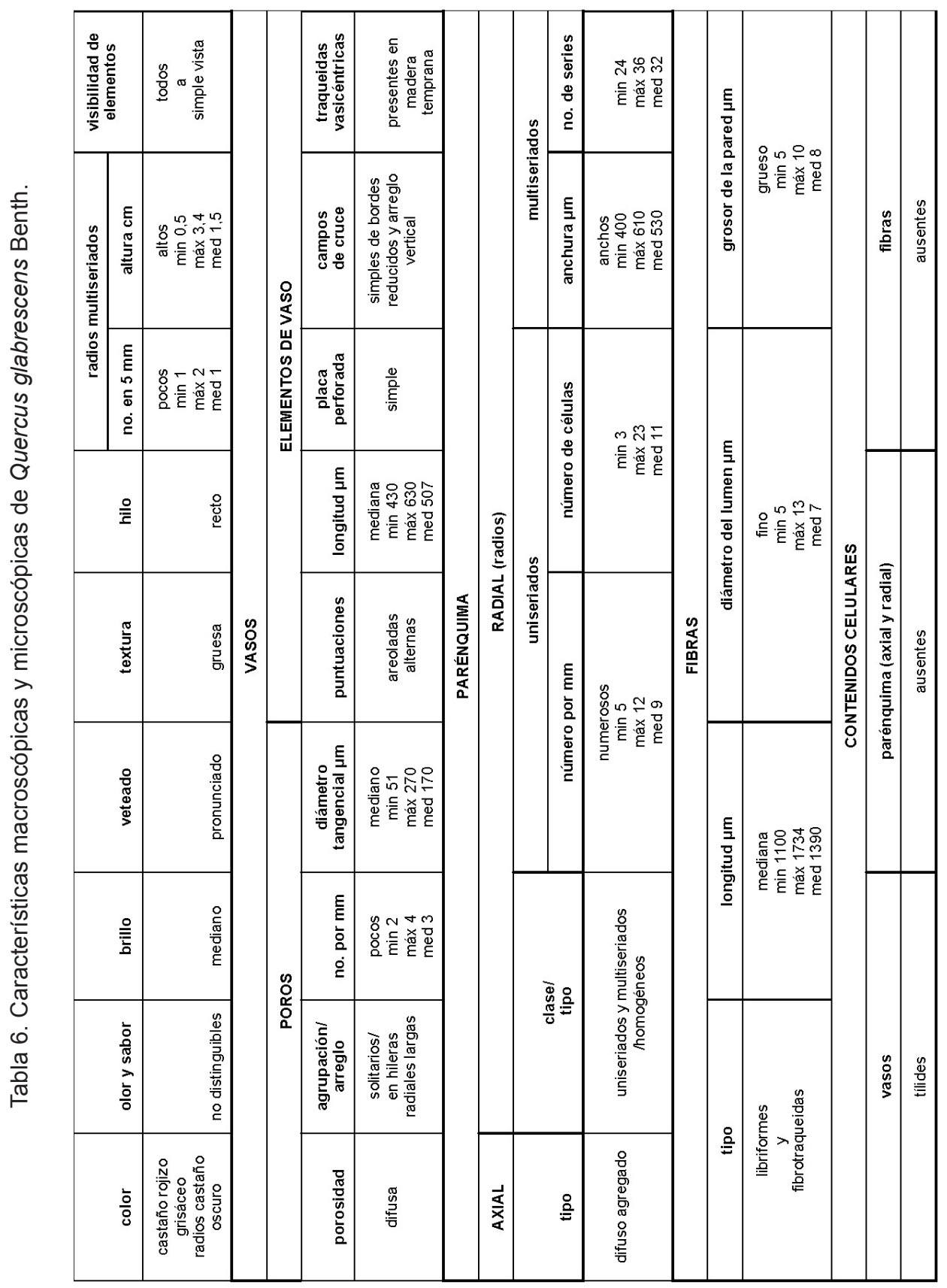




\section{Quercus obtusata Humb. \& Bonpl. (Lám. 6)}

Nombres comunes: encino, encino blanco, encino negro, encino avellano, encino prieto, encino calichahuatl, casahuicahuatl y encino roble.

Distribución: Nuevo León, Tamaulipas, Durango, Zacatecas, San Luis Potosí, Nayarit, Jalisco, Colima, Michoacán, Guerrero, Oaxaca, Guanajuato, Querétaro, Hidalgo, Tlaxcala, México, Distrito Federal, Morelos, Puebla y Veracruz.

Características botánicas (Lám. 6a)

Árbol de 6 a $16 \mathrm{~m}$ de alto, con tronco de 30 a $45 \mathrm{~cm}$ de diámetro, ramillas delgadas, de 2 a $3 \mathrm{~mm}$ de diámetro, de color grisáceo. Hojas oblanceoladooblongas u obovadas de 10 a $20 \mathrm{~cm}$ de largo por 4 a $6 \mathrm{~cm}$ de ancho, margen ondulado-crenado o dentado. Fruto (bellota) ovoide de 15 a $18 \mathrm{~mm}$ de largo, anual, varios agrupados en un pedúnculo de 1 a $9 \mathrm{~cm}$ de largo.

\section{Características macroscópicas de la madera (Tabla 7 y Lám. 6b-6c)}

La madera presenta diferencia de color entre albura y duramen. La albura es de color blanco (10YR 8/1) y el duramen es de color castaño amarillo claro (10YR $6 / 4)$. Los radios multiseriados en la albura son de color gris castaño claro (10YR 4/2) contrastando levemente con los demás elementos celulares. Los radios multise- riados en el duramen son de color castaño oscuro (10YR 4/3) contrastando con los demás elementos celulares. No tiene olor ni sabor, el brillo es mediano, el veteado pronunciado, la textura gruesa y el hilo recto. Los anillos de crecimiento están marcados por una hilera de fibras.

Características microscópicas de la madera (Tabla 7 y Lám. 6d-6f)

La madera presenta porosidad difusa. Los poros son exclusivamente solitarios y se arreglan en hileras diagonales. Son poco numerosos, de contorno oval y circular, de diámetro tangencial mediano. Los elementos de vaso son de longitud mediana, con platina de perforación simple, paredes terminales oblicuas y punteaduras areoladas alternas de forma oval. Las punteaduras vaso-radio son simples, con bordes reducidos y arreglo vertical. Alrededor de algunos vasos de la madera temprana se encuentran traqueidas vasicéntricas. Los vasos presentan gran cantidad de tílides. El parénquima axial es difuso en agregados. Presenta gran cantidad de cristales de forma romboidal. Los radios son uniseriados y multiseriados, homogéneos, formados por células procumbentes. Los primeros son numerosos, de 11 células de altura. Los multiseriados son poco numerosos, altos y extremadamente anchos. Presentan taninos y gomas. Las fibras son de tipo libriforme y fibrotraqueidas, de longitud mediana, diámetro fino y pared muy gruesa. 

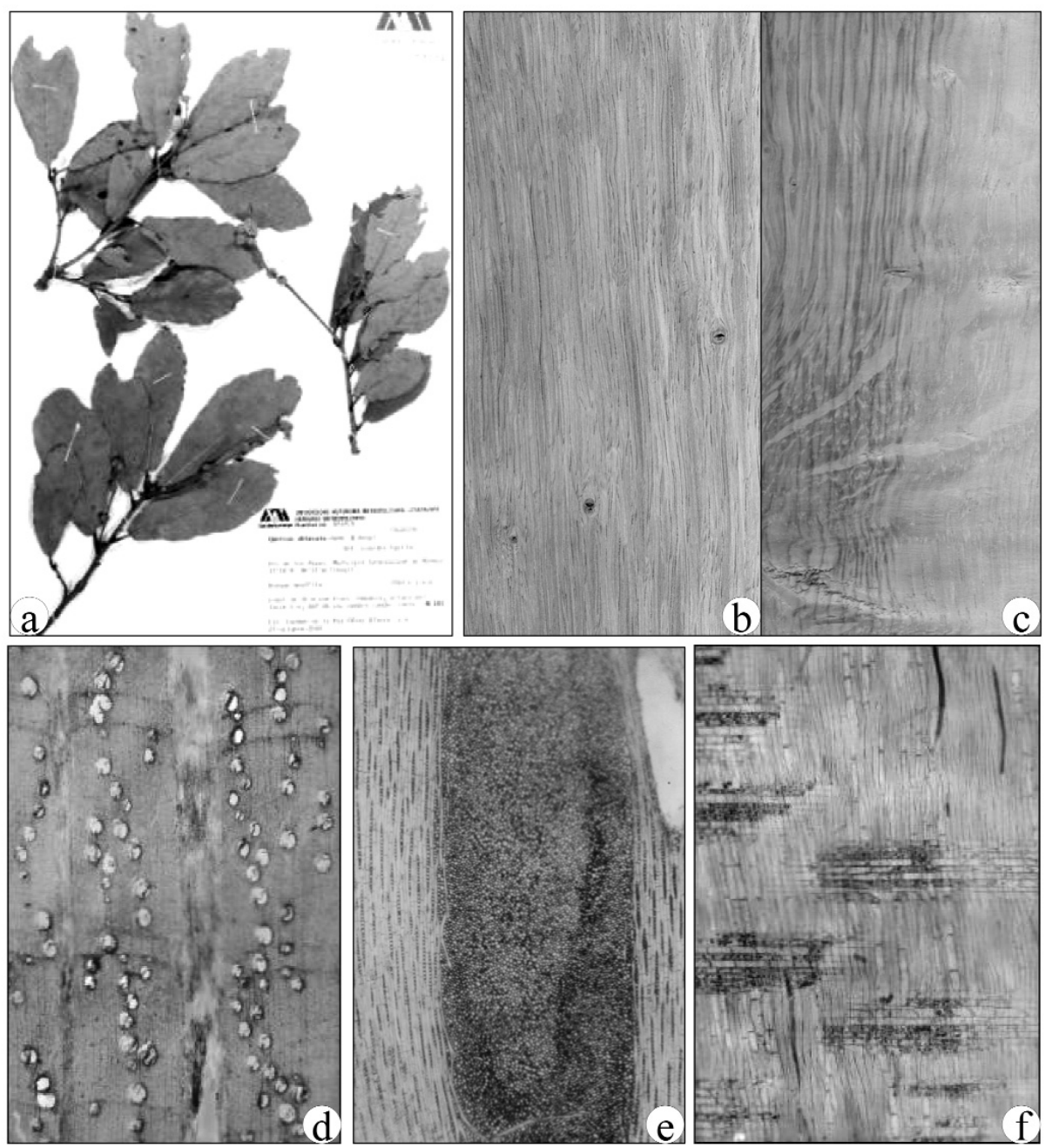

Lámina 6. Quercus obtusata Humb. \& Bonpl. (a) Ejemplar de herbario. (b) Tablilla tangencial. (c) Tablilla radial. (d) Corte transversal (2,5x). (e) Corte tangencial $(2,5 \mathrm{x})$. (f) Corte radial $(10 \mathrm{x})$ 


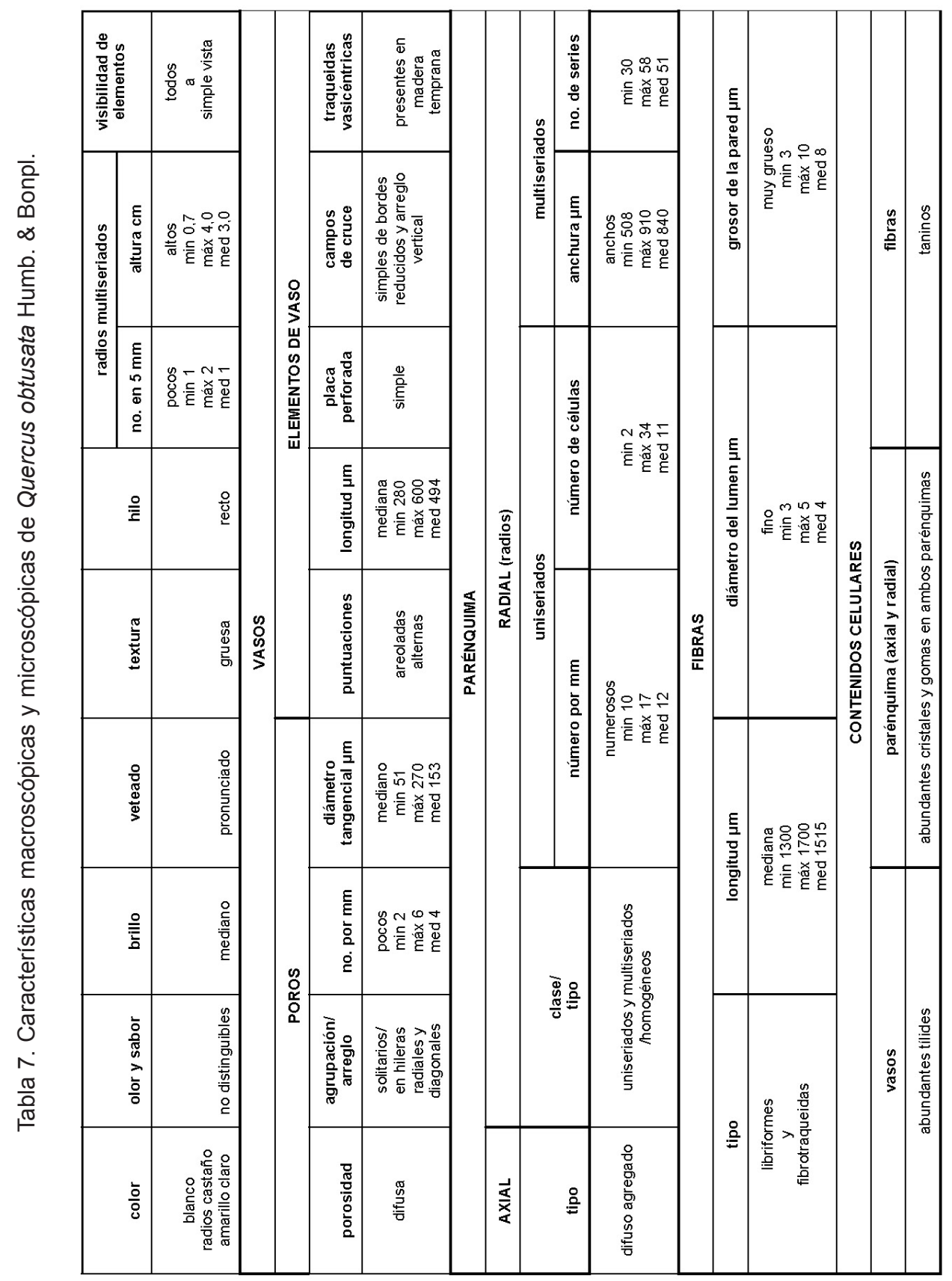




\section{Quercus peduncularis Née (Lám. 7)}

Nombres comunes: encino roble y encino negro.

Distribución: Jalisco, Michoacán, Guerrero, Oaxaca, Chiapas, México y Veracruz.

Características botánicas (Lám. 7a)

Árbol de 2 a $18 \mathrm{~m}$ de alto, con tronco hasta de $75 \mathrm{~cm}$ de diámetro, con ramillas de 1 a $5 \mathrm{~mm}$ de diámetro, de color castaño, con lenticelas pálidas y muy visibles. Hojas gruesas y coriáceas de 6 a 16 $\mathrm{cm}$ de largo por 3 a 10 de ancho, obovadas ocasionalmente oblanceoladas o elípticas, margen ondulado-dentado o aserrado, revoluto. Fruto (bellota) ovoide, de $15 \mathrm{~mm}$ de largo, pubescente, anual, solitario o en grupos, en un pedúnculo de $4 \mathrm{~mm}$ de largo o a veces sésil.

Características macroscópicas de la madera (Tabla 8 y Lám. 7b-7c)

La madera no presenta diferencia de color entre albura y duramen, es de color castaño (7.5YR 5/3). Los radios multiseriados son de color castaño oscuro (7.5YR 4/3) contrastando con los demás elementos celulares. No tiene olor ni sabor, el brillo es mediano, el veteado pronunciado, la textura gruesa y el hilo recto. Los anillos de crecimiento están bien delimitados por una hilera de fibras.

Características microscópicas de la madera (Tabla 8 y Lám. 7d-7f)

La madera presenta porosidad difusa. Los poros son exclusivamente solitarios y se arreglan en forma dendrítica. Son poco numerosos, de contorno oval y circular, de diámetro tangencial mediano. Los elementos de vaso son de longitud mediana, con platina de perforación simple, paredes terminales oblicuas y punteaduras areoladas alternas de forma oval. Las punteaduras vaso-radio son simples, con bordes reducidos y arreglo vertical. Alrededor de algunos vasos de la madera temprana se encuentran traqueidas vasicéntricas. Los vasos presentan gran cantidad de tílides. El parénquima axial es difuso en agregados. Presenta gran cantidad de gomas. Los radios son uniseriados y multiseriados, homogéneos y formados por células procumbentes. Los primeros son numerosos, de 8 células de altura. Los multiseriados son poco numerosos, altos y muy anchos, con pocos cristales de forma romboidal. Las fibras son de tipo libriforme y fibrotraqueidas, de longitud mediana, diámetro fino y pared muy gruesa. 

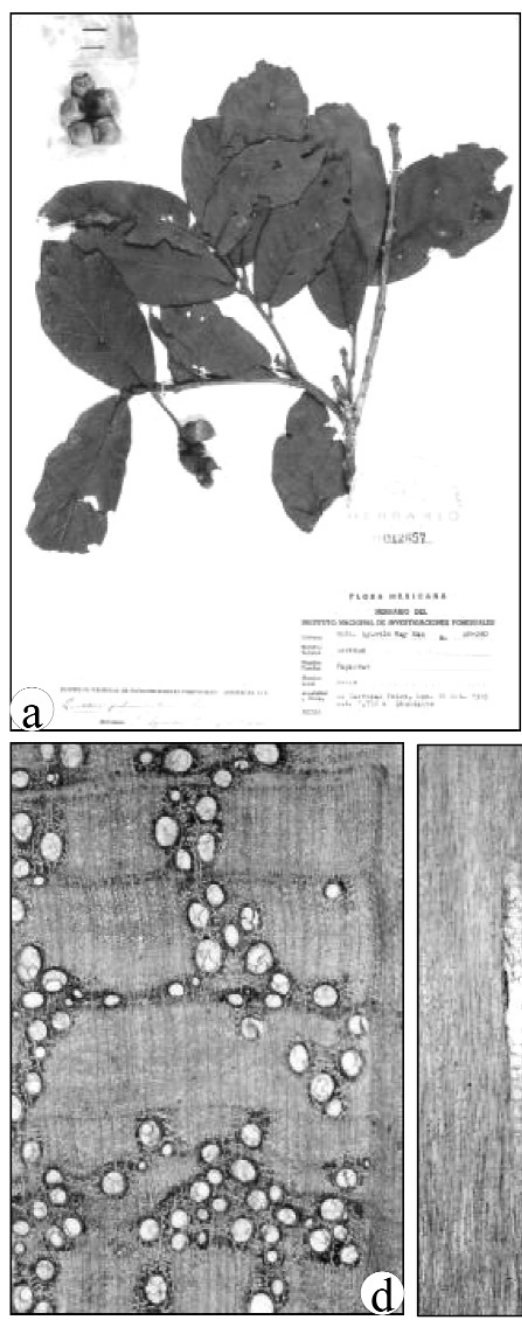
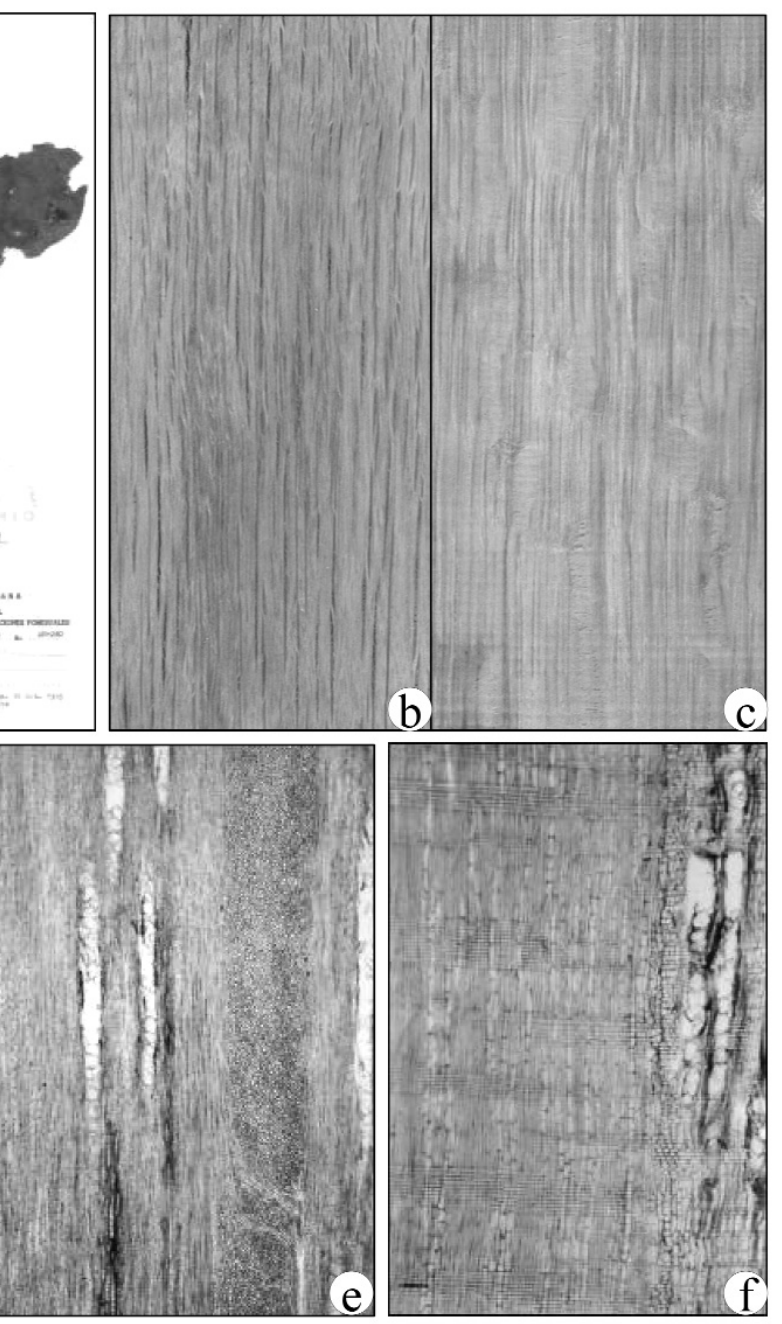

Lámina 7. Quercus peduncularis Née (a) Ejemplar de herbario. (b) Tablilla tangencial. (c) Tablilla radial. (d) Corte transversal $(2,5 x)$. (e) Corte tangencial $(2,5 x)$.

(f) Corte radial $(10 x)$ 


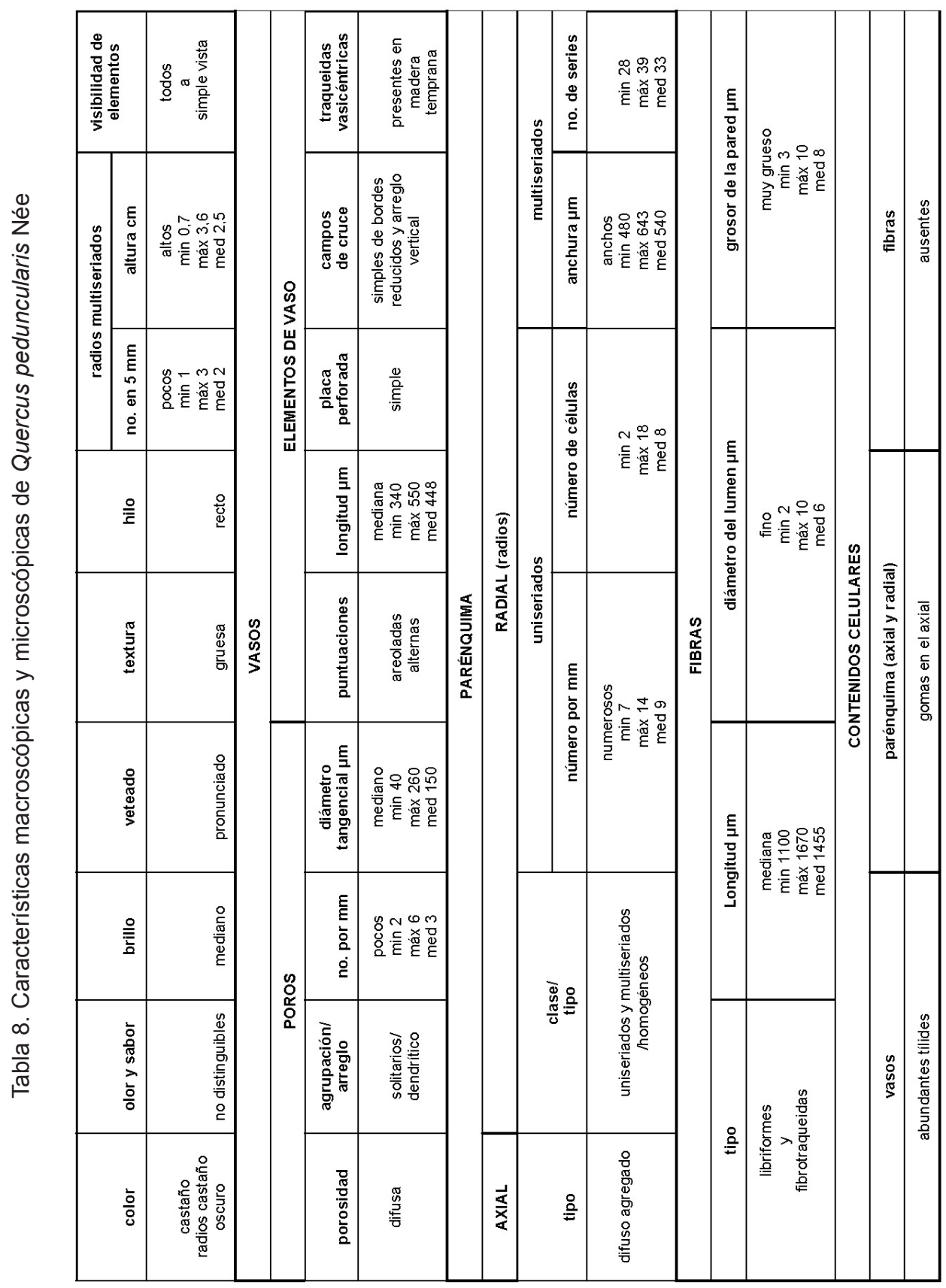


8. Quercus rugosa Née (Lám. 8)

Nombres comunes: encino, encino cuero, encino blanco liso, encino de asta, encino avellano, encino tocuz, encino quebracho, encino roble, encino hojarasca y encino negro.

Distribución: Baja California Sur, Sonora, Chihuahua, Coahuila, Nuevo León, Durango, Zacatecas, San Luis Potosí, Nayarit, Jalisco, Colima, Michoacán, Guerrero, Oaxaca, Chiapas, Aguascalientes, Guanajuato, Querétaro, Hidalgo, Tlaxcala, México, Distrito Federal, Morelos, Puebla y Veracruz.

Características botánicas (Lám. 8a)

Árbol hasta de $20 \mathrm{~m}$ de alto, con tronco de $45 \mathrm{~cm}$ de diámetro, con ramillas fuertes, de 3 a $4 \mathrm{~mm}$ de diámetro y con lenticelas muy visibles. Hojas duras y coriáceas, de 8 a $10 \mathrm{~cm}$ de largo por 3 a 5 de ancho, ampliamente elíptico-obovadas, haz brillante y casi liso, envés tomentoso, margen crenado-aserrado hacia el ápice. Fruto (bellota) ovoide a largamente ovoide, de 12-20 mm de largo, anual, solitario o en grupos de 2 a 3 , en un pedúnculo de 3 a $6 \mathrm{~cm}$ de largo.

Características macroscópicas de la madera (Tabla 9 y Lám. 8b-8c)

La madera presenta diferencia de color entre albura y duramen. La albura es de color castaño muy pálido (10YR 8/3) y el duramen es de color castaño amarillento (10YR 5/3). Los radios multiseriados en la albura son de color gris claro (10YR 7/2) contrastando levemente con los demás elementos celulares. Los radios multiseriados en el duramen son de color castaño grisáceo oscuro (10YR 4/2) contrastando con los demás elementos celulares. No tiene olor ni sabor, el brillo es mediano, el veteado pronunciado, la textura gruesa y el hilo recto. Los anillos de crecimiento no están bien marcados.

Características microscópicas de la madera (Tabla 9 y Lám. 8d-8f)

La madera presenta porosidad difusa. Los poros son exclusivamente solitarios y se arreglan en hileras radiales y diagonales. Son poco numerosos, de contorno oval y circular, de diámetro tangencial mediano. Los elementos de vaso son de longitud mediana, con platina de perforación simple, paredes terminales oblicuas y punteaduras areoladas alternas de forma oval. Las punteaduras vaso-radio son simples, con bordes reducidos y arreglo vertical. Alrededor de algunos vasos de la madera temprana se encuentran traqueidas vasicéntricas. Los vasos presentan gran cantidad de tílides. El parénquima axial es difuso en agregados. Los radios son uniseriados y multiseriados, homogéneos, formados por células procumbentes. Los primeros son numerosos, de 12 células de altura. Los multiseriados son poco numerosos, altos y muy anchos. Presentan gran cantidad de gomas. Las fibras son de tipo libriforme y fibrotraqueidas, de longitud mediana, diámetro fino y pared muy gruesa. 

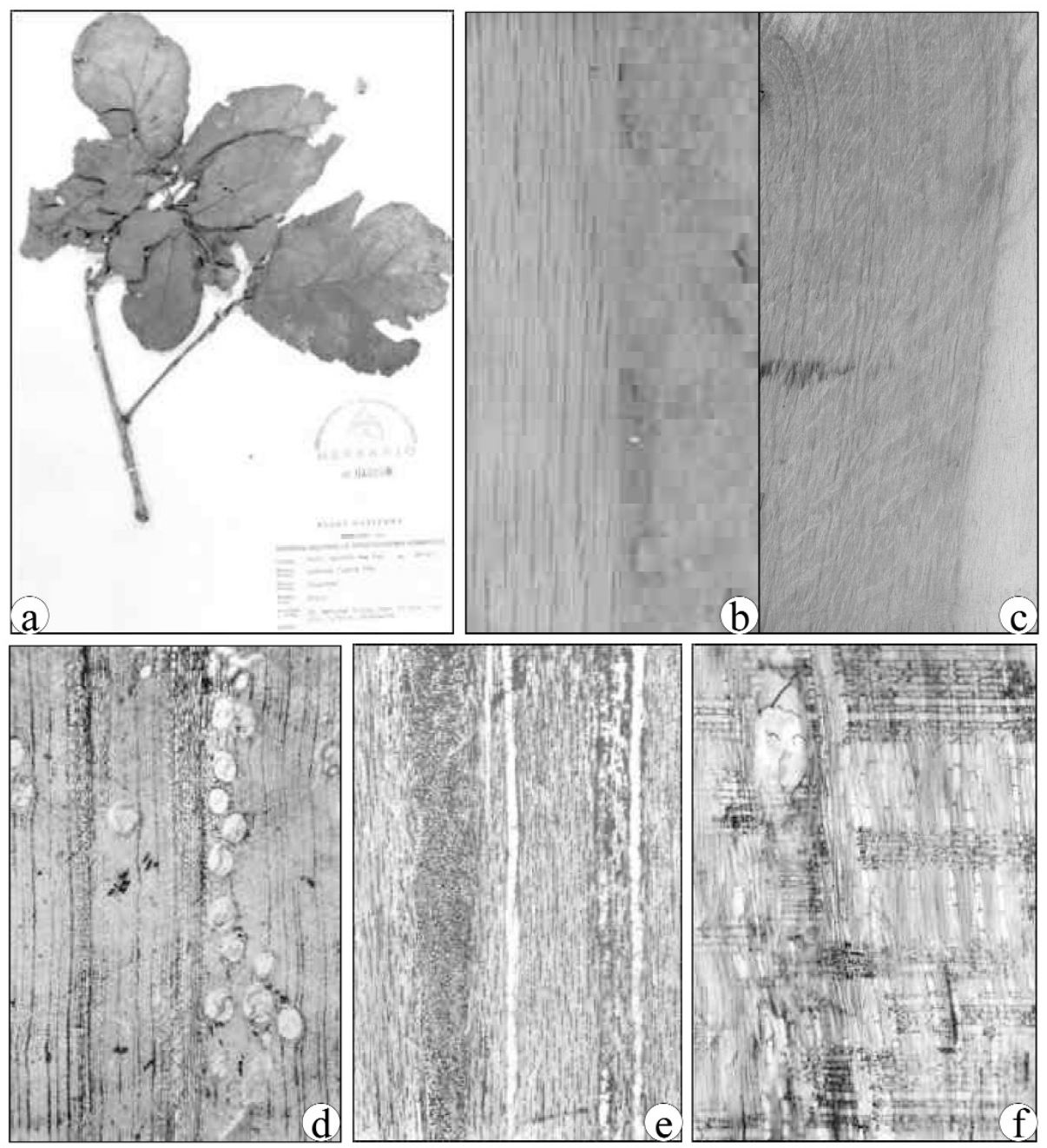

Lámina 8. Quercus rugosa Née (a) Ejemplar de herbario. (b) Tablilla tangencial. (c) Tablilla radial. (d) Corte transversal $(2,5 x)$. (e) Corte tangencial $(2,5 x)$.

(f) Corte radial $(10 \mathrm{x})$ 


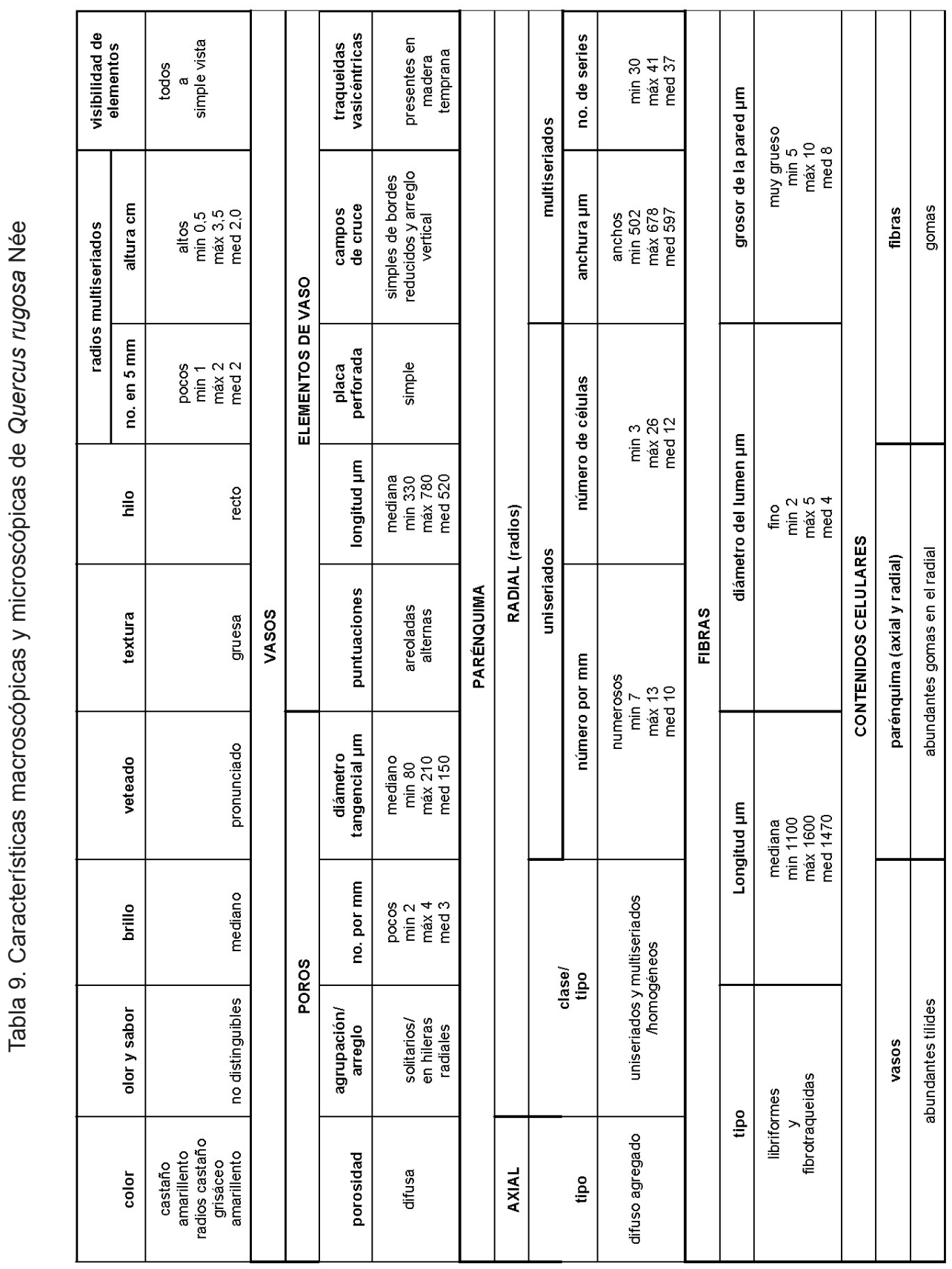




\section{DISCUSIÓN}

La madera de las ocho especies estudiadas tiene características macroscópicas semejantes (el olor y sabor no distinguible, el brillo mediano, el veteado pronunciado, la textura gruesa y el hilo recto), aunque las dimensiones de los radios multiseriados hacen que el veteado sea más pronunciado y la textura más gruesa en las especies de encinos blancos (Tablas 2 al 9, Lám. 1 al 8, letra b-c).

En lo que a las características microscópicas se refiere, todas las especies presentan poros solitarios, poco numerosos, de contorno oval o circular, con los elementos de vaso con platinas de perforación simple, paredes terminales oblicuas y punteaduras areoladas alternas, las punteaduras vaso-radio son simples, de bordes reducidos y arreglo vertical. Alrededor de algunos vasos se presentan traqueidas vasicéntricas, parénquima difuso en agregados, radios uniseriados y multiseriados de tipo homogéneo y fibras libriformes y fibrotraqueidas (Lám. 1 a la 8, letras b, c, d y Tablas 2 al 9). Sin embargo, existen diferencias entre ellas que influyen de manera importante en sus propiedades tecnológicas, las cuales deben considerarse en su manejo y aprovechamiento, como son la presencia de porosidad semianular o difusa (que modifica el tamaño y la abundancia de los vasos), la anchura de los anillos de crecimiento, las dimensiones y la abundancia de los radios multiseriados, las dimensiones de las fibras y la abundancia y el tipo de contenidos celulares.

Las cuatro especies del subgénero Erythrobalanus presentan los anillos de crecimiento más anchos que los de las especies blancas y, dentro de éstas, $Q$. peduncularis, tiene los más angostos (Lám. 1 a la 8, letra c). En el caso de las maderas con porosidad anular y semia- nular, dependiendo del ancho de los anillos se tendrá diferente calidad de las mismas. Una madera ligera contiene anillos angostos, y una pesada, anchos; el grosor de los anillos es un carácter altamente influenciado por el medio y por lo tanto muy manejable y preferido en silvicultura. De las especies estudiadas, $Q$. affinis, Q. conzatti y $Q$. laurina presentan porosidad semianular.

Otra de las diferencias notables entre los subgéneros, es la que se refiere a las dimensiones de los radios multiseriados, que es la estructura más sobresaliente de la madera de los encinos y que junto con las fibras, tienen un papel importante en sus propiedades tecnológicas. En $Q$. affinis, $Q$. conzatti y $Q$. laurina (encinos rojos) se presentan los radios multiseriados más cortos y angostos y en Q. obtusata (encino blanco) los más altos y más anchos (Lám. $1,3,4,6$, letras c y d).

La longitud, el diámetro y sobre todo el grosor de la pared de las fibras son características que influyen en las propiedades de cualquier madera. De manera general las especies de Quercus, independientemente del subgénero al que pertenezcan, presentan abundantes fibras, pero dentro de las especies aquí estudiadas, las blancas tienen las fibras más largas y con paredes gruesas, resultando ser maderas más duras y más pesadas que las rojas, lo que aunado con las dimensiones de los radios multiseriados, resalta la importancia de darles un manejo acorde con sus características, trabajándolas por separado, principalmente en el aserrío y en el secado, de acuerdo con las normas de trabajo adecuadas.

Las especies blancas presentan tílides, cristales, gomas y taninos. Las especies rojas presentan pocas tílides. Quercus laurina además tiene taninos y 
Q. conzatti, tílides y cristales. $Q$. scytophylla no presenta ningún contenido de estos (Lám. 1 a la 8, letras c, d, e). Los contenidos en los encinos rojos nunca son tan abundantes como los que presentan las especies blancas.

Es importante hacer notar que los estudios sobre las propiedades tecnológicas de la madera, en los que se incluyen datos anatómicos, proporcionan información que permite hacer un mejor aprovechamiento de este recurso forestal, ya que la información obtenida puede ser de gran utilidad para la aplicación adecuada de los procesos de transformación. Si consideramos que hasta el momento se conocen las características anatómicas de la madera de alrededor de 40 especies de encinos, incluyendo las del presente estudio, y tomando en cuenta que existen entre 135 y 140 especies en nuestro país (Zavala,1990; Valencia, 2004), esto representa apenas el $28 \%$ de las especies, quedando un amplio campo por explorar. Además, también es importante estudiar ejemplares de la misma especie, recolectados en diferentes sitios, para conocer cómo influye el medio en las características anatómicas, lo que permitirá conocer las condiciones ambientales donde se desarrollan mejor las especies.

\section{USOS SUGERIDOS}

De acuerdo con las características anatómicas que presentan las maderas de las especies estudiadas, se sugiere que se procesen por separado las especies rojas de las especies blancas. Las especies rojas presentan porosidad semianular, radios multiseriados no tan altos ni tan anchos como en las especies blancas, con pocas series (características que favorecen sus propiedades estéticas), fibras de longitud y pared mediana y contenidos celulares escasos 0 ausentes. Debido a estas características es que tienen menos problemas para el aserrío y el secado. Por ello se recomienda que $Q$. affinis, $Q$. conzatti, $Q$. laurina y $Q$. scytophylla, se utilicen en la elaboración de productos de alta calidad que pongan de manifiesto sus características estéticas tales como: ebanistería, chapa, pisos, lambrín, canceles, accesorios y decoración en general, juguetes, muebles infantiles, partes de instrumentos musicales, artículos torneados en general, cajas, adornos, diversos tipos de recipientes, etcétera.

Dentro del grupo de los encinos blancos, $Q$. glabrescens, $Q$ peduncularis y $Q$. rugosa, presentan los radios multiseriados anchos con varias series, fibras de paredes gruesas y abundantes contenidos celulares (principalmente gomas y tílides). Debido a esto, si se tiene especial cuidado en los tiempos de aserrío y secado, proporcionarían una madera muy recomendable para pisos, escaleras, y otros usos donde se requiera una madera dura y pesada

Por último, Q. obtusata, que presenta los radios multiseriados excesivamente anchos y muy altos, abundantes radios uniseriados, fibras largas, de paredes gruesas, muchos cristales en el parénquima axial y radial y abundantes tílides, debe procesarse de manera separada de las otras siete especies. Además, si se logra un buen aserrío y un excelente secado, se tendrá una madera con características estéticas notables sumadas a su dureza y consistencia.

\section{RECONOCIMIENTOS}

Se agradece al Biól. Héctor Mario Aguilar Reyes, director del Centro de Investigación y Gestión Ambiental en el estado de Oaxaca; a los dueños de los predios de los municipios de Capulalpam 
de Méndez y San Pedro Yolox, Oaxaca, las facilidades brindadas para la recolección del material de estudio. A la Biól. Lourdes Aguilar Enríquez, la identificación y revisión de los datos botánicos y de distribución de las especies. A las MMCC Irma Reyes Jaramillo y Ana Rosa López Ferrari la revisión y sugerencias al manuscrito. A la Biól. Patricia Olvera el apoyo en la elaboración de las tablillas y al señor Jorge Lodigiani y al Biól. Exp. Jesús Rivera el procesado del material fotográfico.

\section{REFERENCIAS}

Corral, G. 1981. Anatomía de la madera de siete especies del género Quercus. Bol. Téc. Inst. Nac. Invest. For. núm. 72. México, D. F. 55 p.

De la Paz Pérez O., C. 1974. Anatomía de la madera de 5 especies de encinos de Durango. Bol. Téc. Inst. Nac. Invest. For. núm. 43. México, D. F. $35 \mathrm{p}$.

De la Paz Pérez O, C. 1976. Características anatómicas de cinco encinos de México. Bol. Téc. Inst. Nac. Invest. For. núm. 46. México, D. F. 33 p.

De la Paz Pérez O., C. 1982. Estructura anatómica de cinco especies del género Quercus. Bol. Téc. . Inst. Nac. Invest. For. núm. 88. México, D. F. 63 p.

De la Paz Pérez O., C. 1985. Características anatómicas de siete especies del género Quercus. Bol. Téc. Inst. Nac. Invest. For. núm. 123. México D. F. 70 p.

De la Paz Pérez O. C. 2000. Relación estructura propiedades de la madera de algunas especies de encinos (Quercus) mexicanos. Tesis Doctoral. Facultad de Ciencias. UNAM. $275 \mathrm{p}$.
De la Paz Pérez O., C. y A. Quintanar. 1994. Características anatómicas de la madera de 5 especies del estado de Jalisco. Acta Botánica Mexicana 27:75-87.

De la Paz Pérez O. C., R. Dávalos y E. Guerrero. 2000. Aprovechamiento de la madera de encino en México. Madera y Bosques 6(1):3-13.

Guerrero, L. 1985. Anatomía de algunas angiospermas de la región de Cosautlán de Carbajal. Tesis. Facultad de Ciencias Biológicas. Universidad Veracruzana. 143 p.

INEGI. 1990. División municipal de las entidades federativas. XI Censo General de Población y Vivienda, 1990. 180 p.

INEGI. 2000. Anuario estadístico del estado de Oaxaca. Tomo I. Gobierno del Estado de Oaxaca. 366 p.

IAWA COMMITTEE. 1989. IAWA list of microscopic features for hardwood identification. IAWA Bulletin 10:219-332.

Johansen, D. A. 1940. Plant microtechnique. McGraw-Hill. Nueva York. 523 p.

Martínez, M. 1981. Los encinos de México. Comisión Forestal. Técnica Manejo 8. Mich., México. 358 p.

Munsell Color. 1990. Munsell soil color charts. Baltimore, Maryland. $17 \mathrm{p}$.

Nixon, K. C. 1993. The genus Quercus in Mexico. In: T.P. Ramamoorthy, R. Bye, A. Lot y J. Fay (Eds.). Biological Diversity of Mexico: Origins and Distribution, pp. 447-458, Oxford University Press. Nueva York.

Quintanar, A., C. de la Paz Pérez O., I. Cruz \& D. Razo. 1996. Anatomía de la madera de 8 especies de angios- 
permas de clima templado. Boletín de la Sociedad Botánica de México, 58:5-14.

Rzedowski, J. 1981. Vegetación de México. Limusa. México. 482 p.

Tortorelli, L. 1956. Maderas y bosques argentinos. ACME. Buenos Aires. $910 \mathrm{p}$.

Valencia, S. 2004. Diversidad del género Quercus (Fagaceae) en México.
Boletín de la Sociedad Botánica de México 75: 33-55.

Zavala, F. 1990. Los encinos de México: un recurso desaprovechado. Ciencia y Desarrollo XVI (95):43-51.

Zavala, F. 1995. Encinos y robles. Notas fitogeográficas. División de Ciencias Forestales. Universidad Autónoma Chapingo. $44 \mathrm{p}$. 